\title{
Controlling surface morphology and sensitivity of granular and porous silver films for surface-enhanced Raman scattering, SERS
}

\author{
Sherif Okeil and Jörg J. Schneider ${ }^{\star}$
}

\author{
Full Research Paper \\ Address: \\ Eduard-Zintl-Institut für Anorganische und Physikalische Chemie, \\ Technische Universität Darmstadt, Alarich-Weiss-Straße 12, 64287 \\ Darmstadt, Germany \\ Email: \\ Jörg J. Schneider ${ }^{*}$ - joerg.schneider@ac.chemie.tu-darmstadt.de \\ * Corresponding author \\ Keywords: \\ plasma treatment; silver; sputtering; surface-enhanced Raman \\ spectroscopy (SERS); surface roughening
}

\author{
Beilstein J. Nanotechnol. 2018, 9, 2813-2831. \\ doi:10.3762/bjnano.9.263 \\ Received: 22 May 2018 \\ Accepted: 30 September 2018 \\ Published: 07 November 2018 \\ Associate Editor: C. Jagadish \\ (C) 2018 Okeil and Schneider; licensee Beilstein-Institut. \\ License and terms: see end of document.
}

\begin{abstract}
The design of efficient substrates for surface-enhanced Raman spectroscopy (SERS) for large-scale fabrication at low cost is an important issue in further enhancing the use of SERS for routine chemical analysis. Here, we systematically investigate the effect of different radio frequency (rf) plasmas (argon, hydrogen, nitrogen, air and oxygen plasma) as well as combinations of these plasmas on the surface morphology of thin silver films. It was found that different surface structures and different degrees of surface roughness could be obtained by a systematic variation of the plasma type and condition as well as plasma power and treatment time. The differently roughened silver surfaces act as efficient SERS substrates showing greater enhancement factors compared to as prepared, sputtered, but untreated silver films when using rhodamine B as Raman probe molecule. The obtained roughened silver films were fully characterized by scanning electron microscopy (SEM), atomic force microscopy (AFM), X-ray diffraction (XRD), transmission electron microscopy (TEM), X-ray photoelectron (XPS and Auger) and ultraviolet-visible spectroscopy (UV-vis) as well as contact angle measurements. It was found that different morphologies of the roughened Ag films could be obtained under controlled conditions. These silver films show a broad range of tunable SERS enhancement factors ranging from $1.93 \times 10^{2}$ to $2.35 \times 10^{5}$ using rhodamine B as probe molecule. The main factors that control the enhancement are the plasma gas used and the plasma conditions, i.e., pressure, power and treatment time. Altogether this work shows for the first time the effectiveness of a plasma treatment for surface roughening of silver thin films and its profound influence on the interface-controlled SERS enhancement effect. The method can be used for low-cost, large-scale production of SERS substrates.
\end{abstract}

\section{Introduction}

The great enhancement of Raman signals obtained from molecules when they are in close vicinity to a rough noble-metal surface (e.g., gold, silver and copper) has attracted a great deal of interest in the last decades [1]. This phenomenon, called surface-enhanced Raman scattering [2,3], depends on the fact that incident light leads to the excitation of surface plasmon reso- 
nances, which in turn lead to a concentration of the incident electromagnetic field thus enhancing the Raman scattering effect. This effect is even further enhanced by the presence of so called hot spots, which are sub-10 nm gaps where the electromagnetic field is further magnified due to constructive interference of the plasmon resonances [4]. Electromagnetic enhancement is the main reason for the observed Raman enhancement and depends on the local electromagnetic field at the metal surface while the chemical enhancement depends on the analyte itself and results from an effective charge transfer between the noble metal and the adsorbed probe molecule $[5,6]$.

While the Raman effect is intrinsically weak and typically does not permit the analysis of low concentrations, the SERS signal dramatically enhances the sensitivity typically by orders of magnitude and allows for the analysis of low analyte concentrations [5,7]. The fabrication of SERS substrates began with electrochemical oxidation/reduction cycles especially of silver electrodes. This is the most widely studied synthesis and is still subject to further investigation and optimization to obtain more efficient SERS substrates [2,8-11]. One modification of the electrochemical fabrication of SERS substrates involves the electrochemical etching of silver to obtain porous silver nanostructures [12]. Other routes include the use of gold or silver nanoparticles of different shapes in solution and their assembly on a solid substrate [6,13-17], nanosphere lithography [18-25] as well as nanolithography and nanoimprinting [26-34]. Additional methods appeared in which nanoparticles or metal films are deposited on structured substrates as carbon nanotubes [3539], graphene foam [40], nanorod or nanopillar arrays [41,42], biological scaffolds $[43,44]$, black silicon $[45,46]$, anisotropically etched single-crystal silicon [47], plasma-treated plastic [48] and anodic aluminum oxide films [49-52]. Some methods aim at the fabrication of three -dimensional silver or gold structures, such as oblique-angle vapor deposition used for the fabrication of silver nanorod arrays [53-56], and nanotransfer printing, which was used to build stacks of gold nanorods or nanowires [4]. The production of nanoporous metal films or particles through a dealloying process also emerged as an effective tool for the facile formation of a large number of SERSactive hot spots [57-60]. Recently, other methods emerged with the aim of producing SERS substrates at low cost, enabling their large-scale production. These methods include inkjetprinting and pen-on-paper approaches $[61,62]$.

Plasma treatment has been widely used for the last decades for microelectronics and surface modification in industry [63,64]. A large variety of plasmas exist depending on the excitation source, the operating pressure and the device geometry $[63,65]$. Advantages of the use of a radio frequency (rf) plasma for chemical modification is that no hazardous chemicals and sol- vents are involved. Moreover, it enables a quick chemical modification under ambient conditions in the gas phase [64,66-71]. Thus, plasma treatment could present a straightforward and affordable alternative to the electrochemical roughening of silver and can be even used as a technological reliable alternative for the production of SERS substrates. Interestingly, up to date the use of plasma treatment for SERS applications is still limited $[72,73]$ despite its high potential in modifying metal surfaces. Especially a systematic study is lacking.

Herein we report on our studies towards a systematic investigation of the effect of different rf plasmas on sputtered silver surfaces to determine the potential of plasma treatment in a controlled increase of the surface roughness of silver as well as the formation of hot spots on the silver surface for the use in SERS. To the best of our knowledge this is the first systematic investigation in that direction.

\section{Experimental}

\section{Preparation of sputtered silver films}

Thin films of silver were sputtered on glass substrates cleaned with acetone. Different thicknesses of silver were sputtered using a benchtop Cressington 208HR sputter coater in which the thickness of the sputtered silver layer was monitored by a MTM-20 high-resolution thickness controller. The sputtered silver films are named according to the thickness indicated by the thickness controller. A silver target (99.99\%) from Evochem with $57 \mathrm{~mm}$ diameter and $0.2 \mathrm{~mm}$ thickness was used as sputter target. The deposition rate used was about $0.4 \mathrm{~nm} / \mathrm{s}$ at a chamber pressure of about 0.05 mbar.

\section{Plasma treatment of the prepared silver films}

The sputtered silver films of different thicknesses were treated with different plasma gases using a capacitively coupled rf plasma apparatus operated at $13.56 \mathrm{MHz}$ (Diener electronic, model Femto, Germany) with a maximum power of $200 \mathrm{~W}$. After introduction of the sample into the plasma chamber, where the sample was placed on the lower electrode, the chamber was evacuated to a pressure below $0.2 \mathrm{mbar}$. Then the gas to be used for plasma treatment was introduced at a specified flow rate, controlled by a mass flow controller. When the pressure in the plasma chamber achieved its equilibrium the radio frequency controller was switched on at a specified power and left for a defined period of time to obtain the desired plasma treatment for the silver films. The operating temperature was set at $25{ }^{\circ} \mathrm{C}$ but heating occurred during the plasma treatment depending on the plasma treatment time. The gases used for plasma treatment were argon at a pressure of 1.5 mbar for a flow rate of $16.7 \mathrm{sccm}$, nitrogen at a pressure of $0.8 \mathrm{mbar}$ for a flow rate of $12 \mathrm{sccm}$, hydrogen at a pressure of 0.22 mbar for a flow rate of $6 \mathrm{sccm}$ and $0.38 \mathrm{mbar}$ for a flow rate of $12 \mathrm{sccm}$, 
oxygen at a pressure of $0.4 \mathrm{mbar}$ for a flow rate of $6 \mathrm{sccm}$ and $0.8 \mathrm{mbar}$ for a flow rate of $12 \mathrm{sccm}$, and finally air at a pressure of $0.8 \mathrm{mbar}$ for a flow rate of $12 \mathrm{sccm}$. When describing the experiments, the used gases get a notation according to the gas flow and power used for the plasma treatment, i.e., a plasma gas with the notation g12-p200 indicates a gas flow of $12 \mathrm{sccm}$ and a power of $200 \mathrm{~W}$, which was used for almost all samples unless otherwise indicated. For simplicity, any sample without notation for gas flow and power has been synthesized using $12 \mathrm{sccm}$ gas flow and a power of $200 \mathrm{~W}$ except for argon plasma where the standard gas flow used is $16.7 \mathrm{sccm}$. Samples obtained under other conditions will get a notation stating the gas flow and power used.

\section{Characterization of the as-prepared silver films}

The prepared silver films were characterized using atomic force microscopy (AFM) in contact mode on a CP-II AFM (BrukerVeeco) with $\mathrm{SiC}$ cantilevers to determine the topography and surface roughness (root mean square roughness, $R_{\mathrm{q}}$ ). Scanning electron microscopy (SEM) of the silver films was performed on a Philips XL-30 FEG using an electron beam at $25 \mathrm{kV}$. Cross-sectional transmission electron microscopy (TEM) images of the silver films were recorded using a Tecnai G2 F20 microscope operating at $200 \mathrm{kV}$ after the use of focused-ion beam (FIB) for sample preparation [74]. X-ray diffraction (XRD) was performed on a Rigaku Miniflex 600@40 kV $15 \mathrm{~mA}$ diffractometer using $\mathrm{Cu} \mathrm{K} \alpha_{1}$ radiation $(\lambda=1.541 \AA$ ). XPS measurements were performed using a K-Alpha XPS spectrometer (ThermoFischer Scientific, East Grinstead, UK). Data acquisition and processing was done using the Thermo Avantage software. All samples were analyzed using a microfocused, monochromated Al K $\alpha$ X-ray source (30-400 $\mu \mathrm{m}$ spot size). The K-Alpha charge compensation system was employed during analysis, using electrons of $8 \mathrm{eV}$ energy and low-energy argon ions to prevent any localized charge build-up. Auger spectroscopy was performed using a PHI 680 (Physical Electronics) scanning Auger nanoprobe operated at an acceleration voltage of $20 \mathrm{keV}$ and a current of $10 \mathrm{nA}$. Sputtering was carried out under ultra-high vacuum $\left(5 \times 10^{-9}\right.$ Torr $)$, with an argon gun operated at $250 \mathrm{eV}$ and $500 \mathrm{nA}$. The UV-vis spectra of the silver films on glass substrate were recorded by a Thermo Scientific UV-vis spectrophotometer (Evolution 600). The water contact angle was measured using a Krüss DSA 30 model drop-shape analysis system. The water contact angle was measured by placing $5 \mu \mathrm{L}$ water droplets on the silver surface.

\section{Atomic layer deposition (ALD) of $\mathrm{Al}_{2} \mathrm{O}_{3}$}

Silver films on glass substrates were inserted into the ALD chamber (Savannah G2, Ultratech/CNT, Cambridge Nanotech) for deposition of a $1 \mathrm{~nm}$ thick layer of $\mathrm{Al}_{2} \mathrm{O}_{3}$ using trimethyl- aluminium (98+\%, Strem Chemicals, Inc.) and water (HPLC grade, Sigma Aldrich) as precursors at $200{ }^{\circ} \mathrm{C}$. The precursors were vaporized at room temperature and $20 \mathrm{sccm}$ argon was used as carrier gas. The exposure time for both, trimethylaluminium and water, were $0.015 \mathrm{~s}$ and the flushing between the precursor pulses was done with argon for $5 \mathrm{~s}$. For deposition of $1 \mathrm{~nm} \mathrm{Al}{ }_{2} \mathrm{O}_{3}$ ten cycles were carried out.

\section{SERS measurements on the prepared silver films}

Rhodamine B ( $\mathrm{RhB})$ was used as Raman probe to compare the performance of the different silver films. A $10^{-6} \mathrm{M}$ solution of $\mathrm{RhB}$ was prepared in deionized water. A sufficient amount of this solution was dropped on the surface of the silver SERS substrates to cover the surface completely. The SERS substrate was left for $30 \mathrm{~min}$ in the aqueous RhB solution to enable the adsorption of the RhB on the silver surface. After that the SERS substrate was rinsed with deionized water to remove any excess of the RhB. The performance of the different SERS substrates was then evaluated through the measurement of the SERS spectra of RhB using a Horiba Jobin-Yvon LabRAM HR800 microRaman spectrometer employing a $514.5 \mathrm{~nm}$ Ar laser and a 10× objective $(\mathrm{NA}=0.25)$, and a measurement time of $30 \mathrm{~s}$ with a laser power of $1.0 \mathrm{~mW}$. Alternatively, a $632.8 \mathrm{~nm} \mathrm{HeNe}$ laser using a $50 \times$ LWD objective $(\mathrm{NA}=0.5)$ and a measurement time of $30 \mathrm{~s}$ with a laser power of $2.0 \mathrm{~mW}$ was used. For Raman mapping as well as single scans another Raman setup (Alpha300 R micro-Raman, WITec, Germany) with a Nd:YAG $532 \mathrm{~nm}$ laser was used. The samples were exposed to the laser with a power of $1.0 \mathrm{~mW}$ through a $50 \times$ microscope objective $(\mathrm{NA}=0.80)$ resulting in a spot size of about $0.8 \mu \mathrm{m}$. SERS spectra were collected using $1 \mathrm{~s}$ as integration time for single scans. For Raman mapping a $30 \mu \mathrm{m} \times 30 \mu \mathrm{m}$ area was scanned, collecting 900 points (30 lines with 30 points each). The same parameters as for single scans were used. A commercial SERS substrate provided from Abacus (Analytical Systems $\mathrm{GmbH}$ ) consisting of silver nanoparticles on a paper substrate was used for comparison.

\section{Results and Discussion Processing and characterization of sputtered and plasma-treated silver films}

Radio frequency plasma is generated through exposing the feed gas to an external radio frequency field using a frequency of 13.56 MHz. The setup consists simply of two parallel plates about $10 \mathrm{~cm}$ apart where the substrate is placed on the bottom electrode. These electrodes are connected to radio frequency generator generating the alternating electric field at $13.56 \mathrm{MHz}$ frequency (Scheme S1, Supporting Information File 1). At this frequency, electrons quickly respond to any minor changes in the electric field thus gaining a significant amount of energy. 
When these highly energetic electrons collide with the feed gas atoms or molecules this results into a series of successive complex processes, namely ionization (1 and 2), excitation (3) and relaxation (4) as well as dissociation in case of diatomic species (5) [75]:

(1) electron impact ionization: $\mathrm{e}^{-}+\mathrm{A} \longrightarrow \mathrm{A}^{+}+2 \mathrm{e}^{-}$

(2) electron attachment: $\mathrm{e}^{-}+\mathrm{A} \longrightarrow \mathrm{A}^{-}$

(3) excitation: $\mathrm{e}^{-}+\mathrm{A} \longrightarrow \mathrm{A}^{*}+\mathrm{e}^{-}$

(4) relaxation: $\mathrm{A}^{*} \longrightarrow \mathrm{A}+h \mathrm{v}$

(5) dissociation: $\mathrm{e}^{-}+\mathrm{A}_{2} \longrightarrow 2 \mathrm{~A}^{\bullet}+\mathrm{e}^{-}$

Thus controlled rf plasma treatment is a very interesting technique for the modification of surfaces as a number of different chemical species can be generated at low temperature in the gas phase, which can strongly interact with the exposed surface leading to distinct physical and chemical changes $[63,76]$. Therefore, it is interesting to investigate the influence of different kinds of rf plasmas on the surface of thin silver films, which are important substrates for SERS applications due to their great SERS enhancement factors. The question is whether plasma treatment can beneficially modify the thin silver films leading to an enhancement of their SERS activity or vice versa. Scheme 1 gives an overview of the steps performed in fabrication of the SERS substrates and their subsequent studies.

\section{As-sputtered silver films}

Different thicknesses of silver have been sputtered on cleaned glass substrates. At very low thicknesses up to about $20 \mathrm{~nm}$ a transparent silver film could be observed, which became increasingly reflective and finally non-transparent with increasing thickness (Figure 1a,b).

Low-magnification SEM images of freshly sputtered silver films (10 and $200 \mathrm{~nm}$ ) show no significant structural features, which confirms the uniformity of the sputtered silver films. In the $10 \mathrm{~nm}$ thick silver film small grains adjacent to each other together with some voids are observed due island formation during sputtering (Figure 1c,d) [77]. The granular morphology could be advantageous for the formation of hot spots resulting in an efficient SERS activity of the silver film. For the $200 \mathrm{~nm}$ thick silver film the coalescence of the adjacent silver clusters formed in the early stages of the sputtering deposition is visible, leading to a continuous silver film having a visible surface roughness. The sputter deposition yields silver films with a certain surface roughness (Figure 1e,f), which appears to be useful for SERS applications. However, in order to increase this initial surface roughness even more and to create further potential hot spots for increased SERS performance, systematic rf plasma treatments under different conditions were investigated.

\section{Formation of hydrogen plasma treated silver films}

Employing hydrogen plasma treatment $(200 \mathrm{~W})$ using a gas flow rate of $12 \mathrm{sccm}$ results in a chamber pressure of 0.38 mbar. The maximum treatment time was set to $2 \mathrm{~min}$ for the ultrathin $10 \mathrm{~nm}$ silver films. For the $200 \mathrm{~nm}$ silver hydrogen plasma treatment was performed for 5, 15, 30 and $45 \mathrm{~min}$. The SEM images in Figure 2 and Figure S1 (Supporting Information File 1) reveal black spots on the silver surface that become

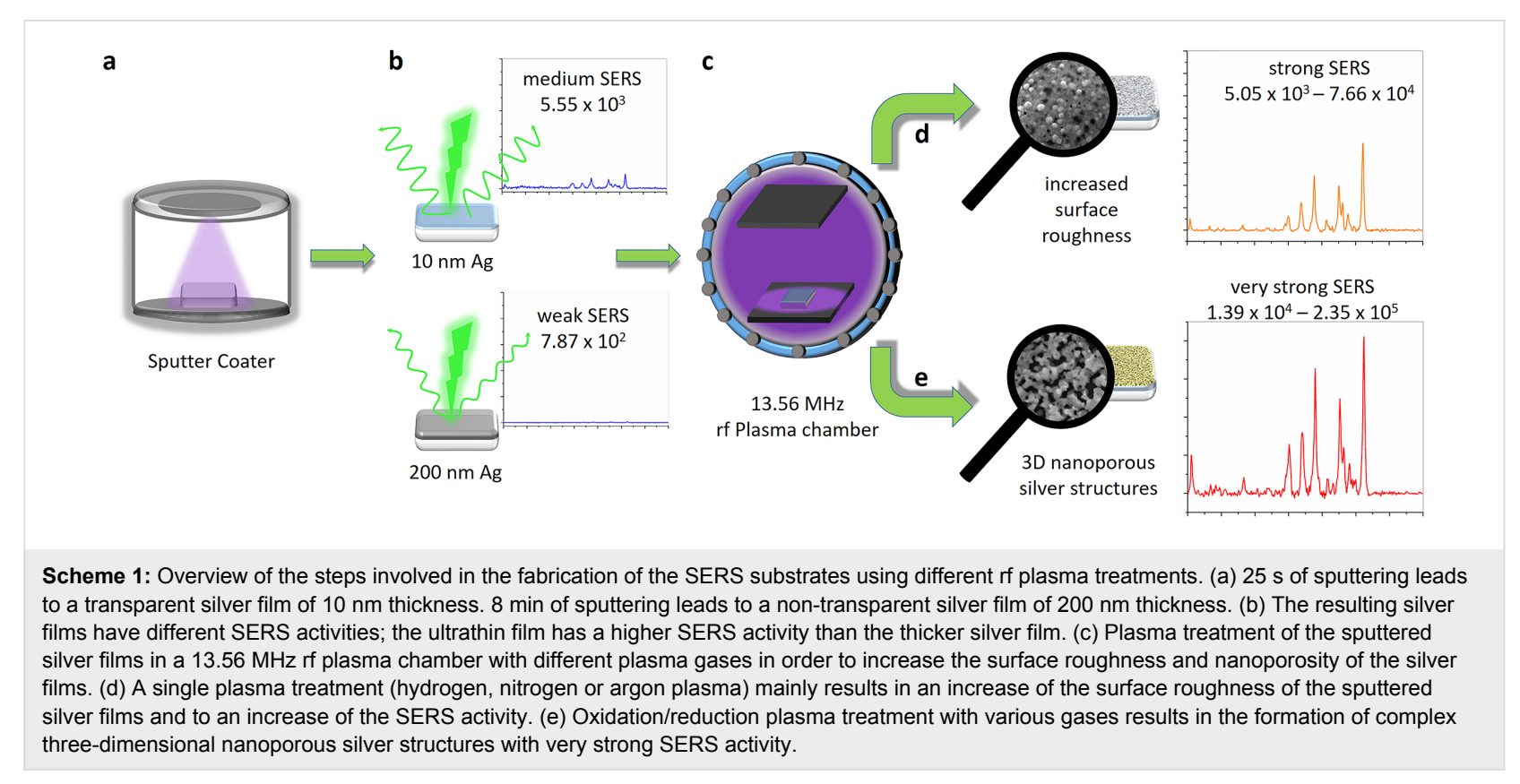



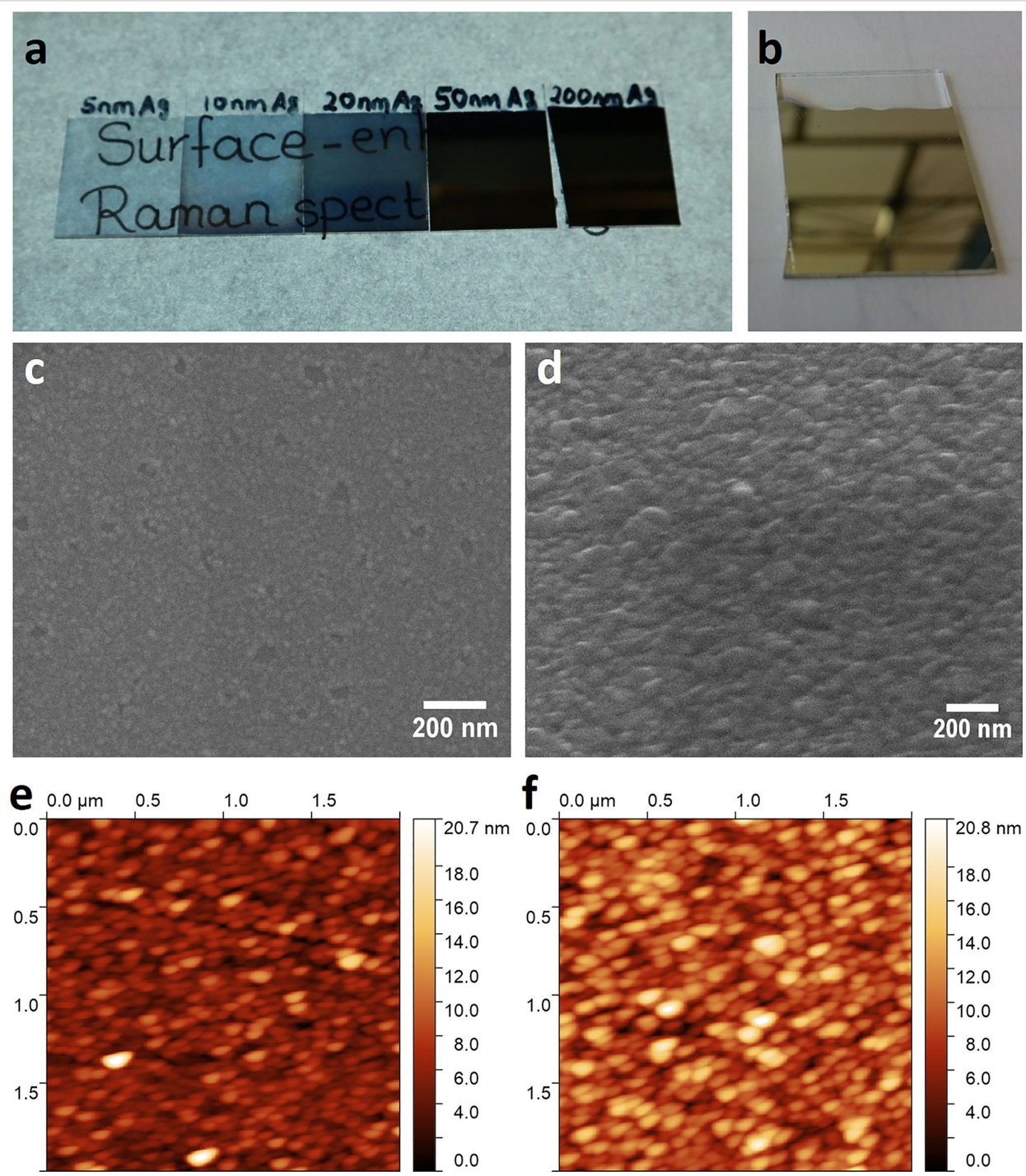

Figure 1: (a) Photograph of sputtered silver films on glass substrates with different thicknesses. From left to right: $5,10,20,50$ and $200 \mathrm{~nm}$.

(b) Photograph showing the mirror-like appearance of the $200 \mathrm{~nm}$ silver film. SEM images of (c) $10 \mathrm{~nm}$ and (d) $200 \mathrm{~nm}$ silver films. AFM images of (e) $10 \mathrm{~nm}\left(R_{\mathrm{q}}=2.02 \mathrm{~nm}\right)$ and (f) $200 \mathrm{~nm}\left(R_{\mathrm{q}}=2.79 \mathrm{~nm}\right)$ sputtered silver films.

darker and increase in size with increasing hydrogen plasma treatment time. These areas show the formation of holes in the silver film which deepen and increase in size with increasing hydrogen plasma treatment time. Using AFM (Figure S2, Supporting Information File 1) it shows that surface roughness increases from $2.02 \mathrm{~nm}$ for an untreated silver film to $5.03 \mathrm{~nm}$ for $5 \mathrm{~min}, 6.29 \mathrm{~nm}$ for $15 \mathrm{~min}$ and $6.85 \mathrm{~nm}$ for $45 \mathrm{~min}$ hydrogen plasma treatment time. The relatively small increase in surface roughness when going from 15 to $45 \mathrm{~min}$ can be explained by the fact that with increasing hydrogen plasma treatment time the etched holes become deeper but at the same time silver is etched away from the surface leading to a decrease in the overall film thickness. Thus, the overall peak-to-valley distance will not change much. A cross-sectional SEM of the silver films before and after hydrogen plasma treatment (Figure 2d) clearly reveals the presence of holes as well as a decrease in the silver film thickness from about $152 \mathrm{~nm}$ to about $71 \mathrm{~nm}$ supporting the claim that the silver is effectively etched away by hydrogen plasma with an average etch rate of $2.7 \mathrm{~nm} / \mathrm{min}$. Etching of silver films by means of hydrogen plasma in an inductively coupled plasma system has also been previously observed and the reasons for this etching could be ion bombardment leading to physical sputtering together with chemical etching for which the formation of a silver dihydride anion $\left(\mathrm{AgH}_{2}{ }^{-}\right)$as etching product has been suggested as it is more stable than silver hydride [78]. As can be seen in the top SEM images (Figure $2 \mathrm{a}-\mathrm{c}$ ) and in the cross-sectional SEM images (Figure 2d) holes are formed in the silver film, which increase in size and depth with increasing hydrogen plasma treatment time. The formation of the holes can be mainly attributed to 

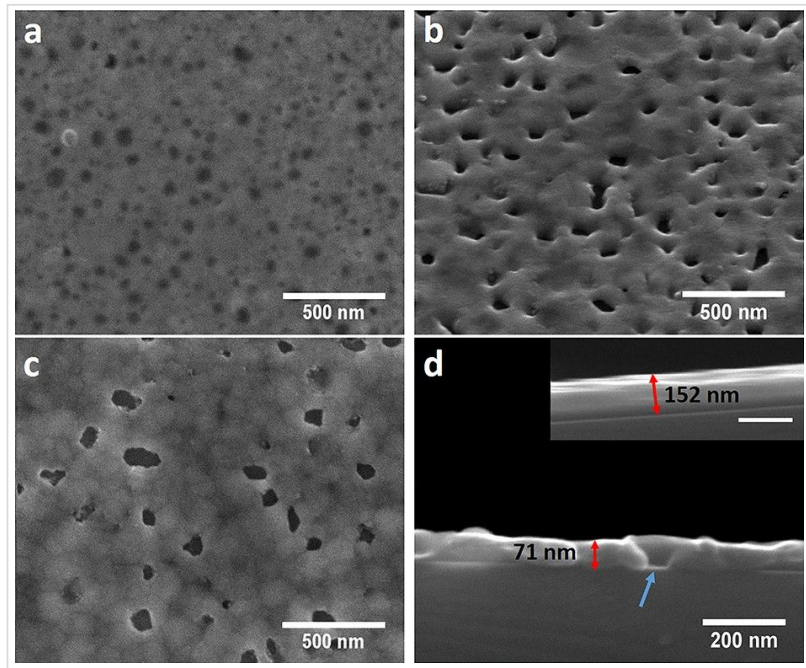

Figure 2: SEM image of a $200 \mathrm{~nm}$ sputtered silver film treated with hydrogen plasma (g12-p200) for (a) $5 \mathrm{~min}$, (b) $30 \mathrm{~min}$ (taken at $45^{\circ}$ tilt) and (c) $45 \mathrm{~min}$ at $100000 \times$ magnification showing the formation of etched holes and increasing grain structure of the silver film. (d) Crosssectional SEM image of a $200 \mathrm{~nm}$ sputtered silver film after 30 min of hydrogen plasma treatment (g12-p200) depicting the actual lowered thickness of the hydrogen plasma-treated silver films compared to the as-sputtered silver film seen in the inset (scale bar: $200 \mathrm{~nm}$ ). The blue arrow indicates a hole in the hydrogen plasma treated silver film.

physical sputtering of silver due to ion bombardment. But at the same time there is a homogenous decrease in the thickness of the silver film, which would point to a chemical etching process that takes place over the whole area exposed to the plasma. Other samples treated with hydrogen plasma using different plasma gas flow conditions and plasma power show the ability of this process for tuning the surface morphology and roughness further (Figure S3, Supporting Information File 1).

\section{Formation of nitrogen plasma treated silver films}

Treatment of the $200 \mathrm{~nm}$ thick silver films with a nitrogen $\mathrm{rf}$ plasma does create a groove-like morphology, which transforms over time (10-60 min) into deeper voids (Figure 3 and Figure S4, Supporting Information File 1). This comes along with an increasing particle formation with increasing treatment time (from 10 to $30 \mathrm{~min}$ ). Furthermore, a faceting of the silver film underlying the formed nanoparticles is visible, which becomes more prominent with increasing nitrogen plasma treatment time from 10 to $60 \mathrm{~min}$ (Figure $3 \mathrm{a}-\mathrm{c}$ ). For the ultrathin $10 \mathrm{~nm}$ film as well as for the $50 \mathrm{~nm}$ film, this granular and facetted surface can be also observed depending on the nitrogen plasma treatment time (Figure S5, Supporting Information File 1). AFM analysis (Figure S6, Supporting Information File 1) revealed a significant increase in the surface roughness of the $200 \mathrm{~nm}$ silver films treated with nitrogen plasma, depending on the treatment time. After $10 \mathrm{~min}$ of nitrogen plasma treatment, the surface roughness $R_{\mathrm{q}}$ was $5.12 \mathrm{~nm}$ and
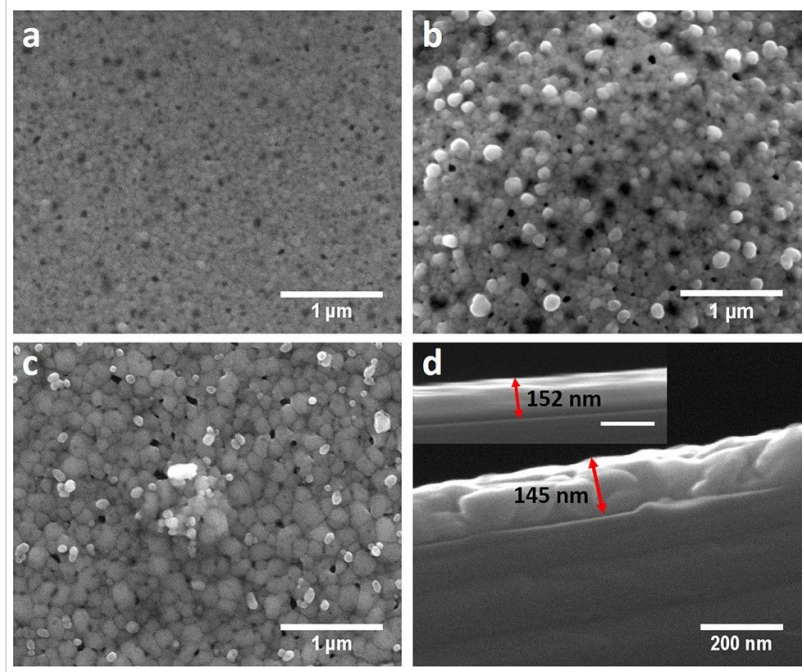

Figure 3: SEM image of a $200 \mathrm{~nm}$ sputtered silver film treated with nitrogen plasma (g12-p200) for (a) $10 \mathrm{~min}$, (b) $30 \mathrm{~min}$ and (c) $60 \mathrm{~min}$ at $50000 \times$ magnification. (d) Cross-sectional SEM image of $200 \mathrm{~nm}$ sputtered silver film treated with nitrogen plasma (g12-p200) for 30 min showing the actual thickness of the prepared silver film after nitrogen plasma treatment compared to the as-sputtered silver film seen in the inset (scale bar is $200 \mathrm{~nm}$ ).

reached $23.1 \mathrm{~nm}$ after $60 \mathrm{~min}$ of treatment. The formation of grooves, which is also observed after hydrogen plasma treatment, is a result of the physical sputtering effect of the silver surface. However, the formation of a particulate morphology and the faceting of the silver surface is best explained by an anisotropic etching or a restructuring process of the silver surface by reactive nitrogen plasma species such as $\mathrm{N}_{2}{ }^{+}, \mathrm{N}_{2}{ }^{*}$ (excited nitrogen), $\mathrm{N}^{\bullet+}$ and $\mathrm{N}^{\bullet}$ (nitrogen radicals) [79]. The faceting of the silver surface is depends on the plasma treatment time when using varying nitrogen plasma treatment parameters and leads to different structural characteristics with respect to the surface roughness (Figure S7 and Figure S8, Supporting Information File 1).

A cross-sectional SEM image of a nitrogen plasma treated silver film (Figure 3d) shows a slight decrease in film thickness compared to untreated silver films, which indicates minor etching by the nitrogen plasma mainly due to ion bombardment. A reasonable explanation for the restructuring of the silver surface, which leads to particle formation and surface faceting could be the in situ formation of silver nitride, which directly decomposes to metallic silver and nitrogen gas [80]. This dynamic process of incorporation of nitrogen followed by its extrusion could lead to a granular structure of the silver surface.

\section{Materials characterization of hydrogen and nitrogen plasma treated silver films}

Neither XPS analysis nor Auger spectroscopy could detect the presence of nitrogen in the nitrogen plasma treated samples 
(Figure 4a and Figures S9-S11 and Table S1 and Table S2, Supporting Information File 1). Even depth profiling using Auger spectroscopy did not reveal any traces of nitrogen (Figure S12, Supporting Information File 1). For further insight, the XPS spectra of untreated sputtered silver, hydrogen plasma treated silver and nitrogen plasma treated silver was compared. The comparison of the $\mathrm{Ag} 3 \mathrm{~d}$ peaks obtained for the three samples shows that there is a slight broadening in the direction of lower binding energies for nitrogen plasma treated silver (Figure 4a and Figure S9a, Supporting Information File 1). Only for the nitrogen plasma treated silver film, a second small peak at $367.63 \mathrm{eV}$ can be fitted besides the main peak at $368.30 \mathrm{eV}$ in the silver $3 \mathrm{~d}$ peaks (Figure $4 \mathrm{a}$ and Figure S9b,c, Supporting Information File 1). Auger spectroscopy of the nitrogen plasma treated silver film shows a typical spectrum in which only the elements silver, carbon, oxygen, and no nitrogen, can be found (Figure S9d, Supporting Information File 1). The reference position of the different elements [81] was inserted and there is a small shift of the silver peak relative to the reference value. The presence of carbon and oxygen, which were also detected by XPS, is due to adventitious carbon and chemisorbed oxygen as the sample was in contact with the atmosphere before the measurement. Although XPS and Auger measurements could not detect nitrogen functionalization on the metal surface, these techniques do reveal that nitrogen plasma treated silver films differ slightly from the as-sputtered films and from the hydrogen plasma treated films. This indicates, together with the different surface structure, a dedicated influence of the nitrogen plasma in addition to the impact of nitrogen ions on the silver surface.

XRD analysis of the $200 \mathrm{~nm}$ as-sputtered silver film as well as hydrogen, nitrogen and argon plasma treated silver films of this thickness show a dependence of the significant and most prominent reflexes on the film texture (Figure 4b). As can be seen from Figure $4 b$ and Figure $4 c$ the preferential orientation of the crystallites is different from that of bulk silver (JCPDS file No. 04-0783). In case of the as-sputtered silver film the crystallites show a preferential (200) orientation. After plasma treatment a gradual change of the preferential orientation can be observed.
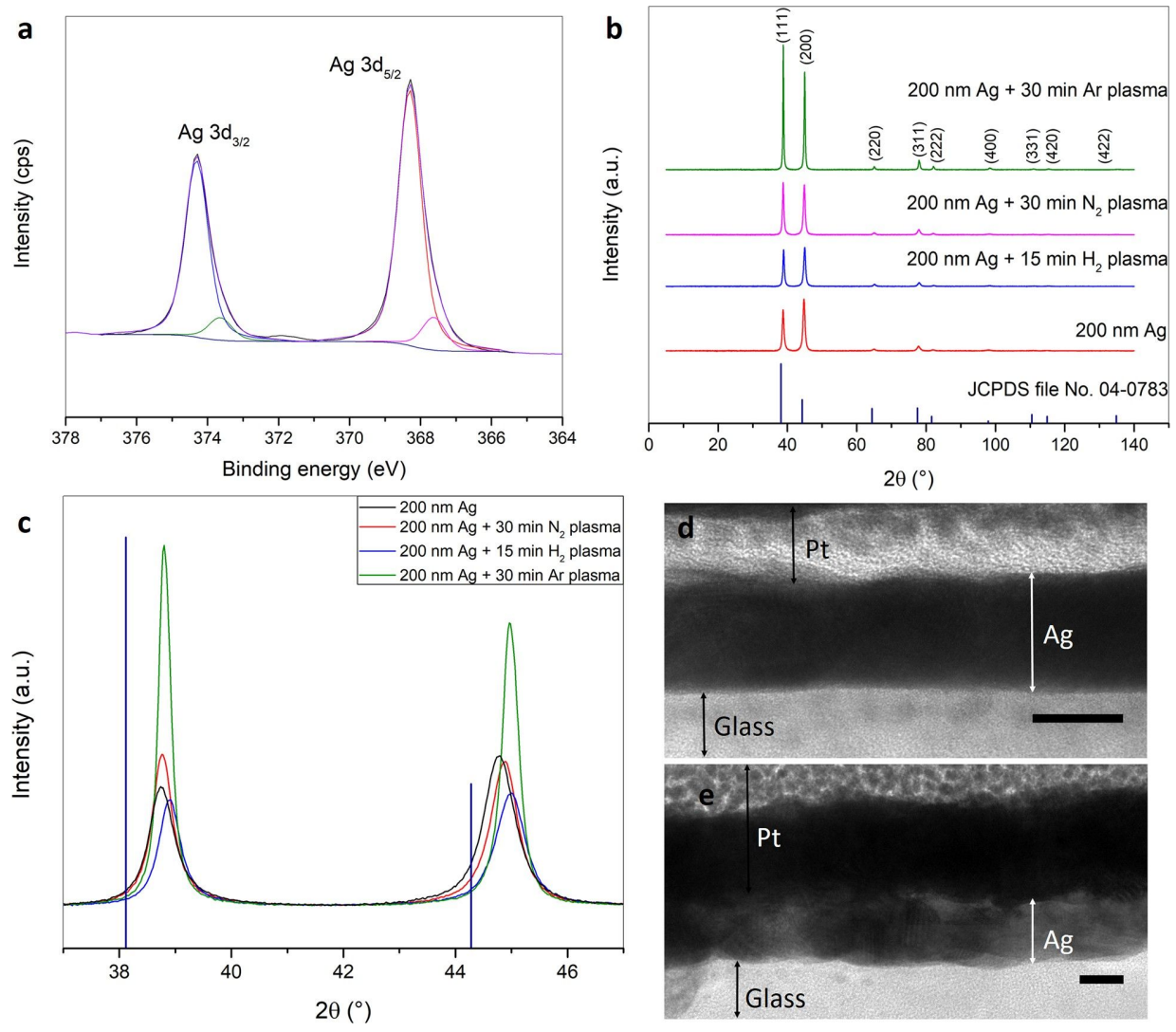

Figure 4: (a) Deconvoluted XPS Ag 3d spectrum for $200 \mathrm{~nm} \mathrm{Ag}+30$ min nitrogen plasma treatment (g12-p200). (b, c) XRD of 200 nm Ag, $200 \mathrm{~nm} \mathrm{Ag}+15$ min hydrogen plasma treatment (g12-p200), $200 \mathrm{~nm} \mathrm{Ag}+30$ min nitrogen plasma treatment (g12-p200),

$200 \mathrm{~nm} \mathrm{Ag}+30 \mathrm{~min}$ argon plasma (g16.7-p200) and their comparison with standard XRD pattern for silver as reference (JCPDS file No. 04-0783). Cross-sectional TEM (FIB) images of (d) an as-sputtered $10 \mathrm{~nm}$ silver film and (e) $10 \mathrm{~nm}$ silver +5 min nitrogen plasma treatment (g12-p200). Scale bar: $10 \mathrm{~nm}$. 
After argon plasma treatment the preferential orientation completely changes to (111). At the same time the peak width and the positions of the (111) and (200) reflexes after different plasma treatments slightly change when compared to those of as-sputtered silver (Figure 4c). This indicates changes in the lattice parameters and thus a change in the macro- and microstrains present in the silver film. All these changes can be explained by the energy transferred to the silver atoms through the impact of high energy ions and electrons on the silver surface during plasma treatment. This leads to an increased mobility of the silver atoms, which either rearrange on the surface by displacement or are completely removed through sputtering.

A comparison of the cross-sectional TEM (FIB) images of an as-sputtered $10 \mathrm{~nm}$ silver film with a $10 \mathrm{~nm}$ silver film treated with nitrogen plasma (g12-p200) for 5 min shows a decrease in the silver film density indicated by a contrast change through which the boundaries of the different crystallites become visible (Figure 4d,e). At the same time, a morphological change of the interface of silver to the substrate is observed. It shows an increased roughness indicating that the plasma treatment affects the complete thickness of the silver film down to the substrate interface.

\section{Argon plasma treated silver films}

Compared to the nitrogen plasma treated silver films, argon plasma treatment of the sputtered silver films resulted in the distinct formation of voids similar to those in the silver films treated with hydrogen plasma. But in contrast to the hydrogen plasma treated films no depth etching effect was observed in the cross-sectional SEM (Figure 5).
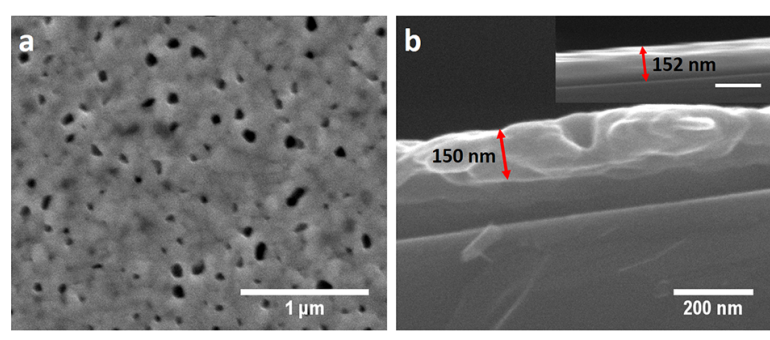

Figure 5: (a) SEM image of $200 \mathrm{~nm}$ sputtered silver film treated with argon plasma (g16.7-p200) for $30 \mathrm{~min}$. (b) Cross-sectional SEM image of $200 \mathrm{~nm}$ sputtered silver film treated with argon plasma (g16.7-p200) for 30 min showing the actual thickness after argon plasma treatment compared to the as-sputtered silver film shown in the inset (scale bar: $200 \mathrm{~nm})$.

\section{Plasma treated silver films under oxidation/ reduction conditions}

Oxygen rf plasmas are well known to efficiently oxidize metallic silver films resulting in granular and nanoporous silver oxide films [73]. For any application in SERS a subsequent reduction to metallic silver is necessary. However, the advantage of this oxidation process is its capability to completely change the morphology of the silver surface converting the originally flat silver surface into a three-dimensional nanoporous surface. The use of hydrogen, nitrogen or even argon plasma as a dry reducing agent would provide an attractive alternative to the often used wet chemical process [75] for obtaining efficient SERS substrates from previously oxidized silver films.

A $200 \mathrm{~nm}$ sputtered silver film was treated with oxygen plasma at a power of $200 \mathrm{~W}$ and a chamber pressure of $0.8 \mathrm{mbar}$ for $15 \mathrm{~min}$. The reduction of the oxidized silver film was performed with a hydrogen plasma at a power of $200 \mathrm{~W}$ and a chamber pressure of $0.38 \mathrm{mbar}$ for $20 \mathrm{~min}$ in order to ensure complete reduction of the silver oxide film. Oxidation of sputtered silver films with oxygen plasma yields a polycrystalline silver oxide film with distinct grain boundaries (Figure 6a). After reduction of the silver oxide film to silver a highly porous structure is formed (Figure 6b). At the same time the drastic increase in film thickness compared to the as-sputtered silver film is observed (Figure 6c). The measured film thickness from the cross-sectional SEM for the oxidized silver film is about $407 \mathrm{~nm}$, which is about 2.7 times the film thickness measured for the sputtered silver film. This large increase in film thickness is obviously due to the formation of silver oxide during the oxygen plasma treatment as a mixture of $\mathrm{Ag}_{2} \mathrm{O}$ and $\mathrm{AgO}$ [82].
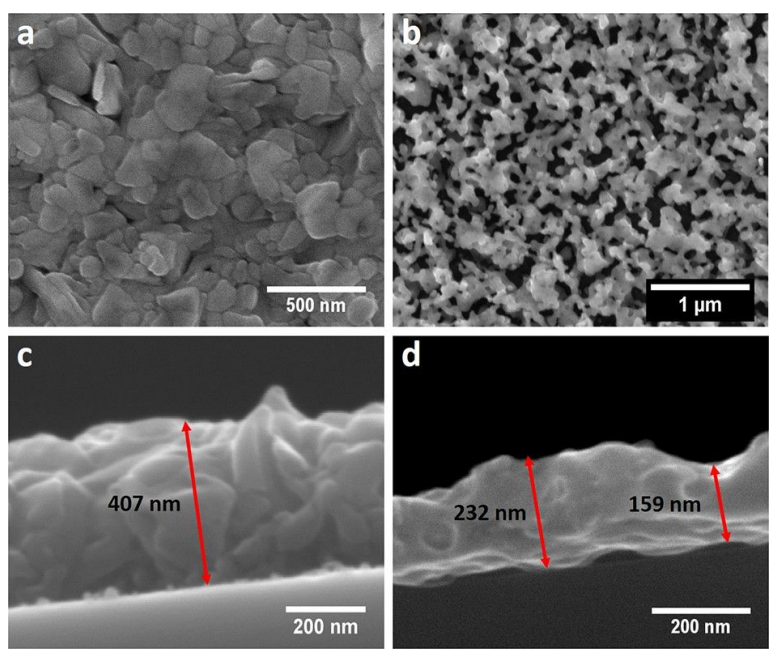

Figure 6: SEM images of a $200 \mathrm{~nm}$ sputtered silver film treated with (a) oxygen plasma (g12-p200) for $15 \mathrm{~min}$ and (b) after reducing the oxidized silver film with hydrogen plasma (g12-p200) for $20 \mathrm{~min}$. Cross-sectional SEM image of $200 \mathrm{~nm}$ sputtered silver film treated with (c) oxygen plasma (g12-p200) for $15 \mathrm{~min}$ and (d) after reducing the oxidized silver film with hydrogen plasma (g12-p200) for $20 \mathrm{~min}$ showing the actual thickness of the prepared silver film after plasma treatment. 
The incorporation of oxygen into the silver lattice leads to a volume expansion and a change in film morphology. The subsequent reduction of this silver oxide film with the hydrogen plasma results in a subsequent film shrinkage back to nearly half of its former value (159-232 nm; Figure 6d) [83,84]. Due to the volume shrinkage the film porosity increases significantly.

Changing plasma treatment time, chamber pressure and plasma power of the oxygen and hydrogen plasmas allows for a further tuning of the morphology of the nanoporous silver films (Figure S13, Supporting Information File 1). Longer treatment with hydrogen plasma can lead to further etching of the pores and the surface after completion of the reduction, while a longer oxygen plasma treatment leads to smaller pores.

An AFM study of the $200 \mathrm{~nm}$ oxidized/reduced silver films proves the drastic increase in surface roughness with increasing oxygen and hydrogen plasma treatment times and plasma power (Figure S14, Supporting Information File 1). A surface roughness $R_{\mathrm{q}}$ of $38.4 \mathrm{~nm}$ was obtained for a $200 \mathrm{~nm}$ sputtered silver film treated for $20 \mathrm{~min}$ with oxygen plasma (g12-p200) followed by another $20 \mathrm{~min}$ of hydrogen plasma (g12-p200) treatment.

If however, the as-sputtered silver film is heated before plasma treatment to $400{ }^{\circ} \mathrm{C}$ for $15 \mathrm{~min}$, dewetting of the continuous silver film into isolated silver particles occurs [85]. Oxidation of these particles by oxygen plasma followed by reduction by hydrogen plasma results in nanoporous particles with a spongy morphology ("silver nanosponges", Figure 7).

In addition, argon plasma was tested as an alternative to hydrogen plasma for the reduction of the silver oxide films obtained after oxygen plasma treatment. In this case the reduction process mainly depends on the electron density of the used plasma. The reduction of silver oxide is facilitated by plasma treatment due to the presence of high-energy UV photons that can easily break the silver-oxygen bond $[78,86]$.

Again a $200 \mathrm{~nm}$ silver film was first oxidized using an oxygen rf plasma for $15 \mathrm{~min}$ at a power of $200 \mathrm{~W}$ and $12 \mathrm{sccm}$ oxygen flow rate (chamber pressure of $0.8 \mathrm{mbar}$ ). After that, the oxidized silver film was reduced using an argon plasma at a power of $200 \mathrm{~W}$ and an argon flow rate of $16.7 \mathrm{sccm}$ (chamber pressure 1.5 mbar). The morphology of the nanoporous silver film is very similar to the one obtained from the reduction using hydrogen as reducing plasma (Figure S15, Supporting Information File 1). Further changes to the oxidation/reduction protocol were made in order to determine whether varying plasma conditions could lead to different 3D silver morphologies. Subse-

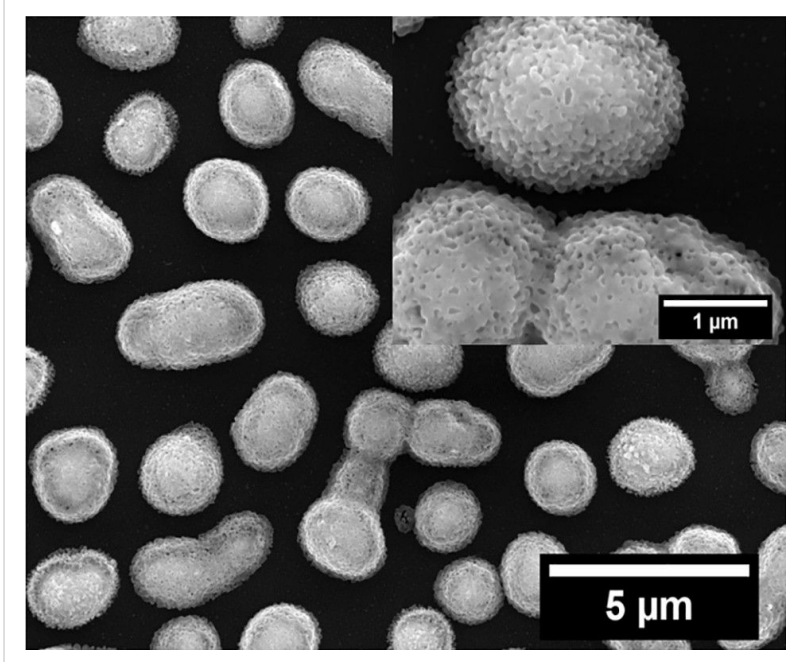

Figure 7: SEM image (10000× magnification) of a $200 \mathrm{~nm}$ sputtered silver film heated at $400{ }^{\circ} \mathrm{C}$ for $15 \mathrm{~min}$ followed by plasma treatment with oxygen plasma (g12-p200) for $10 \mathrm{~min}$ and reduction with hydrogen plasma (g12-p200) for another $10 \mathrm{~min}$. The inset shows particles at $50000 \times$ magnification.

quently, a $200 \mathrm{~nm}$ sputtered silver film was treated with an rf plasma containing a mixture of argon and oxygen gas $(8 \mathrm{sccm}$ argon, $4 \mathrm{sccm}$ oxygen gas flow at a power of $200 \mathrm{~W}$ for $15 \mathrm{~min}$ ). Treatment of the so obtained oxidized silver film with pure argon rf plasma (argon flow rate $16.7 \mathrm{sccm}$, power $200 \mathrm{~W}$, $15 \mathrm{~min}$ ) results in a complex network of interconnected silver particles with large pore size (Figure 8a). This difference in morphology is already observed in the silver film oxidized by the argon/oxygen mixture when compared to the silver film oxidized by oxygen plasma alone (Figure S16a,d, Supporting Information File 1). The difference in the obtained morphologies can eventually be explained by a competing process of oxidation and reduction taking place during the plasma treatment with a mixture of argon and oxygen. Silver might be oxidized, followed by partial reduction both in a dynamic process. To proof this idea further, an rf plasma using air $\left(78.08 \% \mathrm{~N}_{2}\right.$, $20.95 \% \mathrm{O}_{2}$ and $0.97 \%$ other gases) was used for the initial oxidation step (flow rate $12 \mathrm{sccm}, 200 \mathrm{~W}$ for $15 \mathrm{~min}$ ) followed by a reduction using argon plasma for $20 \mathrm{~min}$ (g16.7-p200). SEM reveals again a similar complex network of interconnected silver particles resembling a coral reef as found before when using the argon/oxygen mixture as oxidizing plasma (Figure 8b). Even the silver film oxidized by air plasma for $15 \mathrm{~min}$ and $30 \mathrm{~min}$ as well as the silver film oxidized by the argon/oxygen plasma mixture show different surface structures compared to the silver films oxidized by pure oxygen plasma (Figure S16, Supporting Information File 1). This indicates that the competing oxidation/reduction reactions might play an important role for the in situ structuring of the silver surface. Increasing the plasma treatment time when using an air plasma up 

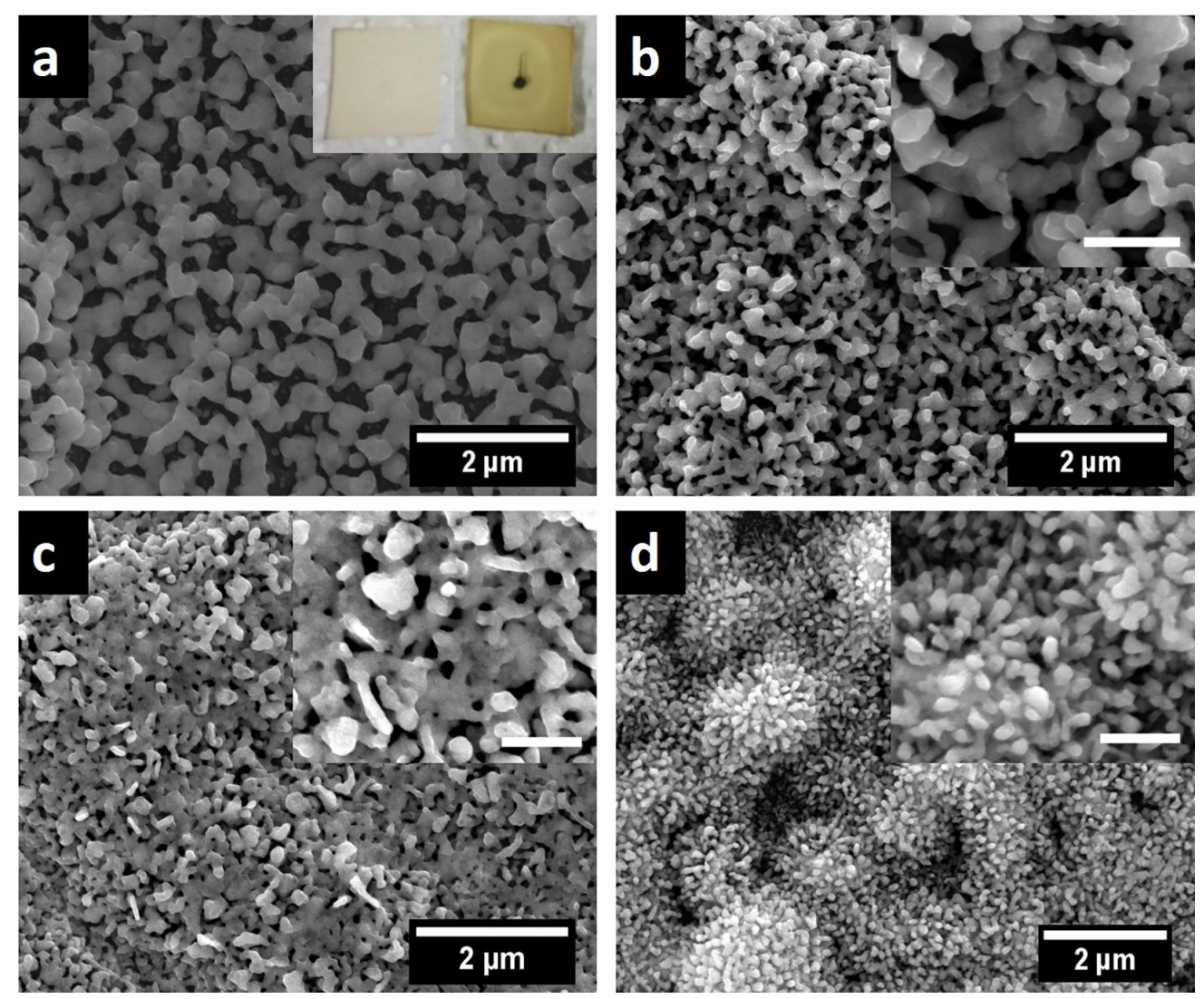

Figure 8: SEM images of a $200 \mathrm{~nm}$ sputtered silver film treated with (a) a mixture of argon ( $8 \mathrm{sccm})$ and oxygen $(4 \mathrm{sccm})$ in an rf plasma (200 W) for $15 \mathrm{~min}$ followed by reduction using a pure argon plasma (g16.7-p200) for $15 \mathrm{~min}$; the inset displays a photograph of the top and the bottom (with black spot) side of the silver film on glass, (b) air plasma (g12-p200) for 15 min followed by reduction with argon plasma (g16.7-p200) for 20 min, (c) air plasma (g12-p200) for $30 \mathrm{~min}$ followed by reduction with argon plasma (g16.7-p200) for $20 \mathrm{~min}$ and (d) $200 \mathrm{~nm}$ sputtered silver film heated at $400{ }^{\circ} \mathrm{C}$ for $15 \mathrm{~min}$ followed by plasma treatment with air plasma (g12-p200) for $15 \mathrm{~min}$ and reduction with argon plasma (g16.7-p200) for another $15 \mathrm{~min}$. The insets are at a $100000 \times$ magnification (scale bar: $500 \mathrm{~nm}$ ).

to 30 min results in an intact porous silver film however with a dense arrangement of short protrusions on the silver particle surfaces (Figure $8 \mathrm{c}$ ). This unique silver morphology might represent the preliminary stage for the coral reef structure obtained with longer argon plasma treatment relative to the plasma oxidation time. Heating an as-prepared silver film for $15 \mathrm{~min}$ at $400{ }^{\circ} \mathrm{C}$ followed by oxidation with air plasma (g12-p200) for $15 \mathrm{~min}$ and reduction with argon plasma (g16.7-p200) for another $15 \mathrm{~min}$ results in silver particles having short rod-like protrusions (Figure 8d). Finally, a reduction with nitrogen plasma was also performed on silver surfaces oxidized by oxygen and air plasma treatment and yielded similar results as those obtained with hydrogen or argon as reducing gases (Figure S17, Supporting Information File 1).

XRD analysis of the silver films after oxidation/reduction proves that the reduction to metallic silver is complete in all cases revealing only the reflexes of elemental silver without any traces of silver oxide (Figure S18, Supporting Information File 1). Comparison of the XRD of the silver nanostructures re- sulting from oxidation/reduction of silver films with as-sputtered silver films shows a variation of the preferential orientation of the silver crystallites in the films. With the systematic combination of oxidizing and reducing rf plasmas and a variation of the different plasma parameters, complex 3D silver nanostructures with tunable surface roughness and nanoporosity can be obtained.

\section{Optical behavior and surface wetting of differently plasma treated silver films}

Figure 9a shows the UV-vis absorption spectra obtained after two different hydrogen rf plasma treatment times in comparison to the silver film before plasma treatment. With increasing hydrogen plasma treatment time, the absorption decreases over the entire spectrum while the decrease is more prominent for longer wavelengths as can be seen for the 2 min hydrogen plasma treatment. This decrease in absorption in the hydrogen plasma treated films might be due to the etching of the silver film. For nitrogen plasma treatment the absorption spectra do not show an overall decrease in absorbance (Figure 9b). While 

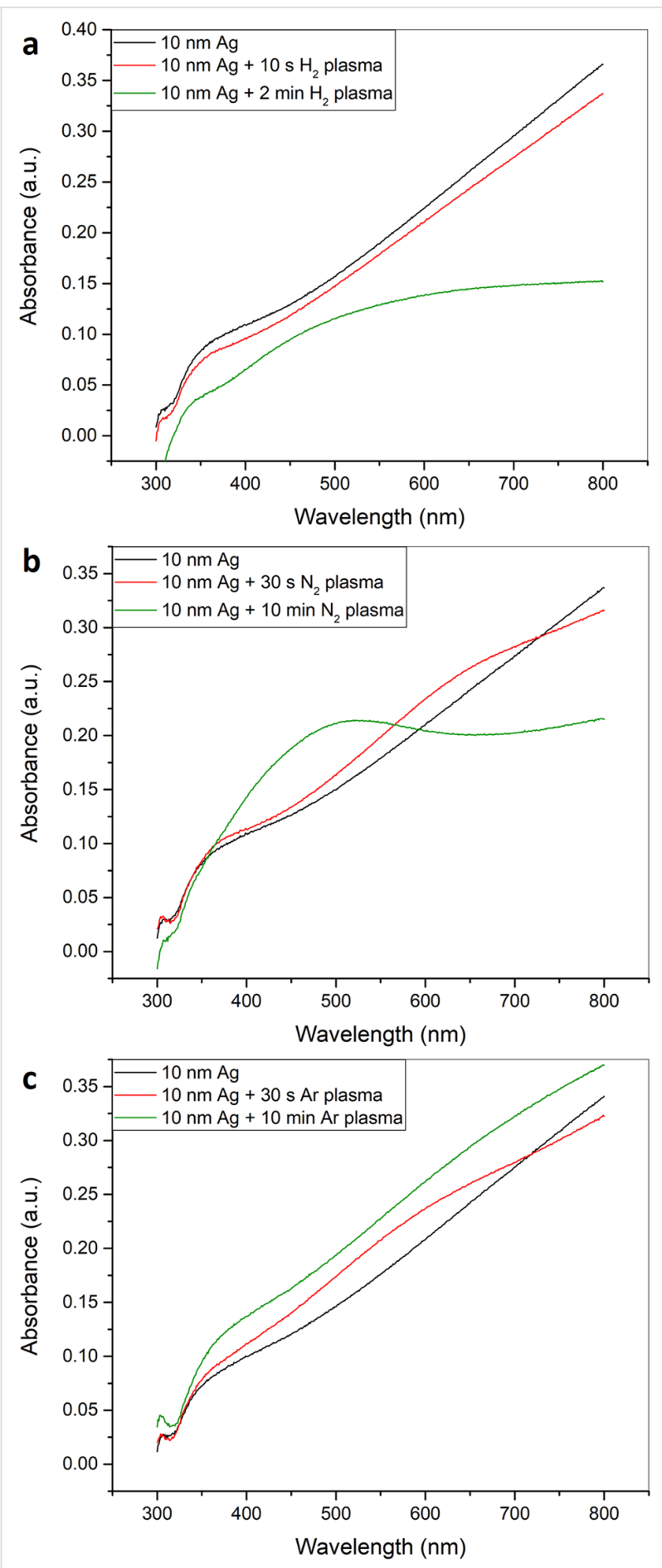

Figure 9: UV-vis spectra of $10 \mathrm{~nm}$ sputtered silver films treated with (a) hydrogen plasma, (b) nitrogen plasma and (c) argon plasma for different times.

the absorbance decreases for longer wavelengths it increases for shorter wavelengths resulting in the formation of an absorption shoulder due to surface plasmons. While this effect is hardly visible for $30 \mathrm{~s}$ nitrogen plasma treatment time at about $650 \mathrm{~nm}$, it becomes much more prominent for $10 \mathrm{~min}$ nitrogen plasma treatment at about $500 \mathrm{~nm}$. This indicates a restructuring of the film surface leading to the formation of particulate structures on the surface as has been proven by SEM. This restructuring might result in the emergence of localized surface plasmon resonances as they are well-known for silver nanoparticles. In case of argon plasma treatment (Figure 9c) increasing plasma treatment time results in an increase of absorption of the silver film over the whole UV-vis spectrum indicating some sort of densification of the silver film [87].

The wetting behavior was analyzed by contact angle measurements of the plasma treated silver films (Figure 10). A change in surface wettability was obtained after the different plasma treatments. Obviously all rf plasma treatments lead to better wettabilities (water contact angles between $44.7^{\circ} \pm 0.11^{\circ}$ and $106.6^{\circ} \pm 0.53^{\circ}$ ) when compared to the as-sputtered silver films (contact angle of $115.2^{\circ} \pm 0.18^{\circ}$ ). This enables a better contact between the analyte in aqueous solution and the SERS substrate. In all cases plasma treatment generates a more hydrophilic silver surface as compared to the as-sputtered silver films manifested by a decrease in the water contact angle. Especially after subsequent oxidation/reduction plasma treatments where nanoporous silver films are obtained, the silver films quickly absorb the droplets through capillary effects thus enabling the analyte to get in good contact with the silver surface.

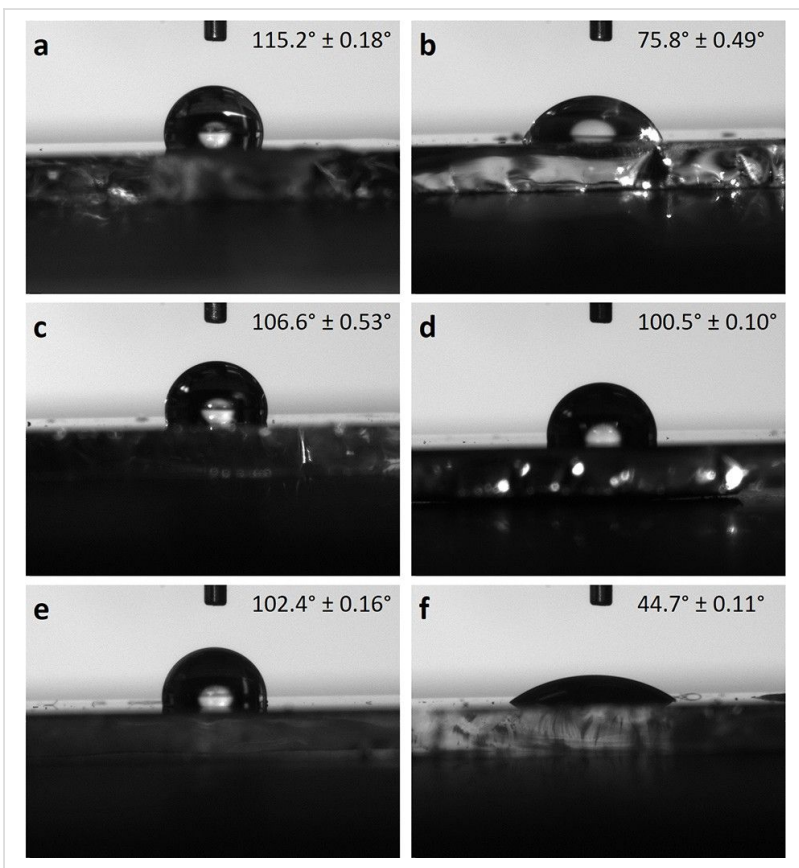

Figure 10: Water contact angle measurements on (a) $200 \mathrm{~nm} \mathrm{Ag}$, (b) $200 \mathrm{~nm} \mathrm{Ag}+15 \mathrm{~min}$ hydrogen plasma (g12-p200),

(c) $200 \mathrm{~nm} \mathrm{Ag}+10 \mathrm{~min}$ nitrogen plasma (g12-p200),

(d) $200 \mathrm{~nm} \mathrm{Ag}+60 \mathrm{~min}$ nitrogen plasma (g12-p200),

(e) $200 \mathrm{~nm} \mathrm{Ag}+15 \mathrm{~min}$ oxygen plasma (g12-p200) + $20 \mathrm{~min}$ hydrogen plasma (g12-p200) and (f) $200 \mathrm{~nm} \mathrm{Ag}+15$ min air plasma (g12$\mathrm{p} 200)+20$ min argon plasma (g16.7-p200). 


\section{Evaluation of the SERS performance of rf-plasma treated silver films}

The SERS effect for the different plasma treated silver films was evaluated in order to determine the influence of the different silver film morphologies obtained by plasma treatment on the SERS performance.

\section{Effect of silver film thickness on SERS performance}

First, the effect of thickness of the as-sputtered silver film on the SERS intensity was evaluated. $5 \mathrm{~nm}, 10 \mathrm{~nm}, 20 \mathrm{~nm}$ and $50 \mathrm{~nm}$ silver films obtained by sputtering were incubated for 30 min with a $10^{-6} \mathrm{M}$ solution of RhB. SERS performance is increasing from $5 \mathrm{~nm}$ to $10 \mathrm{~nm}$ silver films and then decreases again with increasing thickness of the films (Figure 11). This can be attributed to the fact that during the initial stages of sputtering silver islands are formed on the substrate. The distance between these islands decreases with increasing sputtering time until the islands coalesce to form one continuous silver film [77]. Thus for the thinner sputtered silver film $(10 \mathrm{~nm})$ an optimal distance is generated between the silver islands leading to the presence of hot spots and an effective SERS enhancement. With increasing thickness of the films these hot spots disappear leading to a marked decrease in the SERS performance. The $10 \mathrm{~nm}$ sputtered film and $200 \mathrm{~nm}$ sputtered film exhibit similar roughness values (AFM, insets of Figure $2 \mathrm{c}$ and Figure 2d) despite the huge difference in SERS performance.

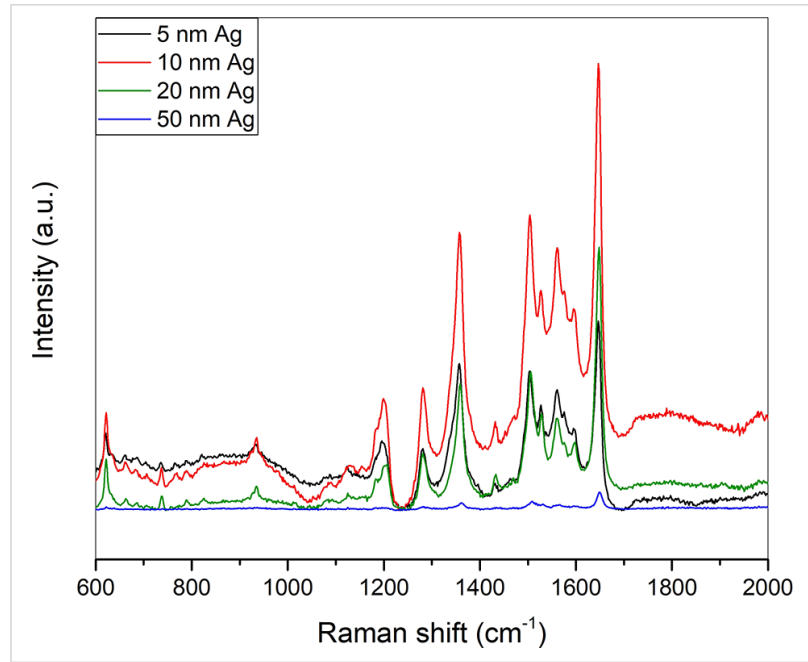

Figure 11: SERS spectra of $10^{-6} \mathrm{M}$ RhB on sputtered silver films of different thicknesses.

This underlines the importance of the generation of hot spots for the evolution of high-intensity SERS spectra.

\section{Effect of single plasma treatment on SERS performance}

Hydrogen plasma treatment (g12-p200) on $10 \mathrm{~nm}$ silver films shows an increase in the SERS intensity with increasing treatment time until $60 \mathrm{~s}$ (Figure 12a,b). After longer hydrogen
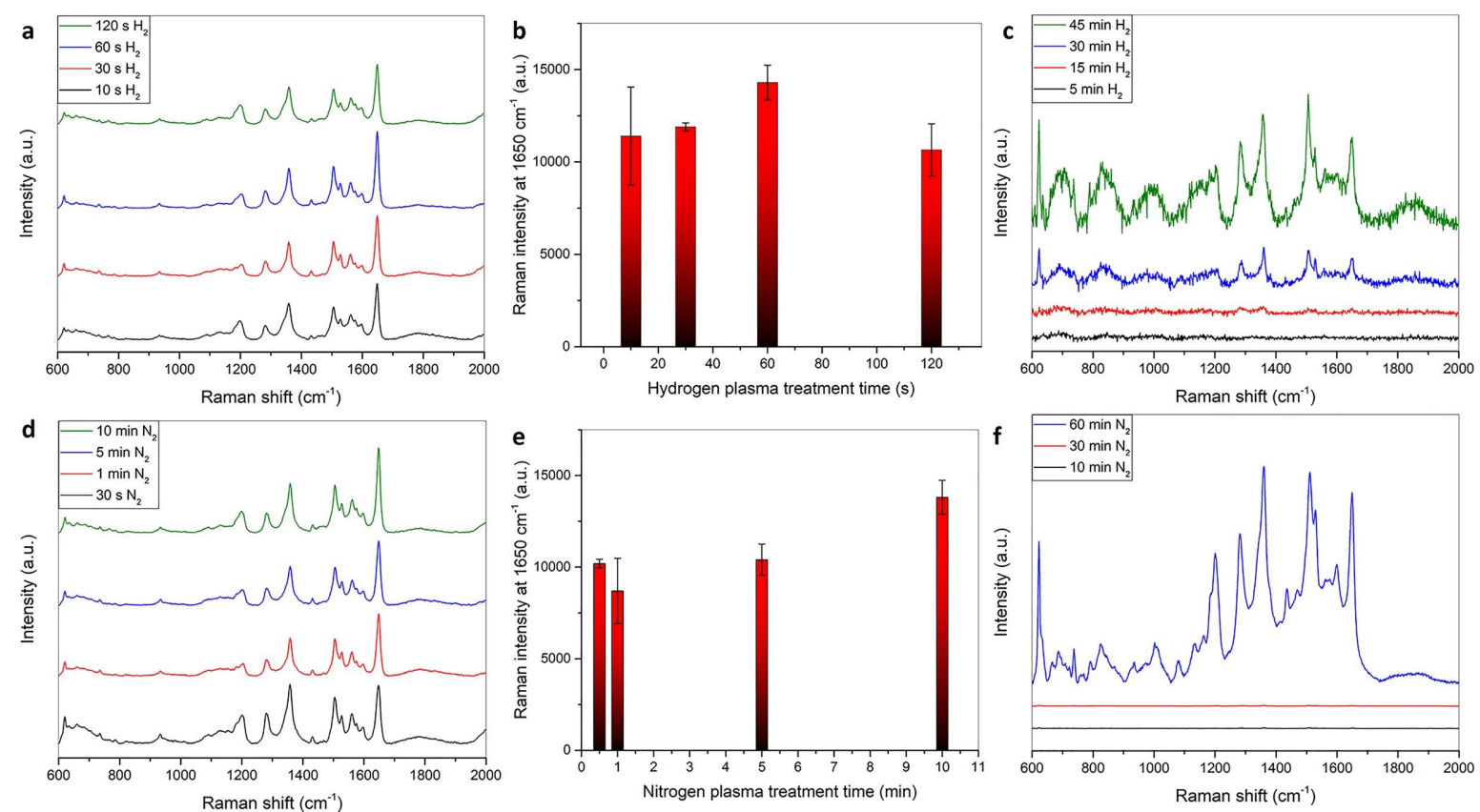

Figure 12: (a) SERS spectra of $10^{-6} \mathrm{M}$ RhB deposited on a $10 \mathrm{~nm}$ silver film treated with hydrogen plasma (g12-p200) using a $514.5 \mathrm{~nm}$ laser. (b) Comparison of the average Raman intensities at $1650 \mathrm{~cm}^{-1}$. (c) SERS spectra of $10^{-6} \mathrm{M}$ RhB on $200 \mathrm{~nm}$ Ag treated with hydrogen plasma (g12p200) using a $632.8 \mathrm{~nm}$ laser. (d) SERS spectra of $10^{-6} \mathrm{M} \mathrm{RhB}$ on a $10 \mathrm{~nm}$ silver film treated with nitrogen plasma (g12-p200) using a $514.5 \mathrm{~nm}$ laser. (e) Comparison of the average Raman intensities at $1650 \mathrm{~cm}^{-1}$. (f) SERS spectra of $10^{-6} \mathrm{M}$ RhB on a $200 \mathrm{~nm}$ silver flm treated with nitrogen plasma (g12-p200) using a $632.8 \mathrm{~nm}$ laser. 
plasma treatment times the SERS intensity decreases, and after about five minutes of hydrogen plasma treatment the silver film has vanished from the glass substrate. This also explains why the SERS intensity decreases with increasing hydrogen plasma treatment time. As earlier corroborated by AFM and SEM (Figure 2 and Figures S1-S3, Supporting Information File 1), the hydrogen plasma increases the surface roughness but at the same time etches the silver layer. Therefore, the SERS intensity increases with very short hydrogen plasma treatment and then rapidly decreases for treatment times over $60 \mathrm{~s}$ for the ultrathin $10 \mathrm{~nm}$ silver film. With $200 \mathrm{~nm}$ silver films the same behavior could be observed (Figure 12c). With increasing hydrogen plasma treatment time, the SERS intensity increases, which is attributed to the increase in surface roughness (see AFM, Figure S2, Supporting Information File 1).

Nitrogen plasma treatment of the silver films (g12-p200) also shows an increase of the SERS intensity (Figure 12d-f). Interestingly, there is a sharp increase in the SERS intensity from 30 to 60 min nitrogen plasma treatment of the $200 \mathrm{~nm}$ silver film, which cannot be explained just by the increase in surface roughness. However, it could be due to a combined effect of increased surface roughness and a matching of the localized surface plasmon resonance with the employed excitation wavelength.

Argon plasma treatment also leads to an increase in the surface roughness and an increase in SERS intensity. Changing the conditions of the plasma treatment leads to the ability to adjust the surface roughness and thus a change in SERS spectra while keeping the treatment time constant (Figure 13).

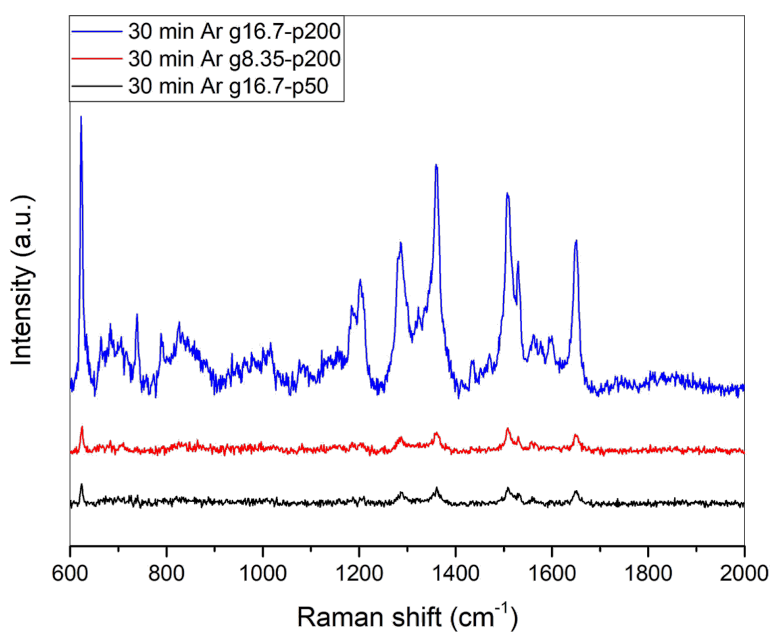

Figure 13: SERS spectra of $10^{-6} \mathrm{M} \mathrm{RhB}$ on a $200 \mathrm{~nm}$ silver film treated with argon plasma for 30 min using different parameters under $632.8 \mathrm{~nm}$ laser excitation.

\section{Effect of oxidation/reduction plasma treatment on SERS performance}

To obtain more complex silver surface morphologies, oxidation followed by reduction of the as-deposited silver films was performed and studied for their SERS activity. As shown in Figure 14a and Figure 14b, different plasma treatment times for oxygen and hydrogen plasma as well as different plasma conditions were tested. As standard conditions a gas flow of $12 \mathrm{sccm}$ was used for both oxygen and hydrogen together with a plasma power of $200 \mathrm{~W}$. It can be noted that increasing the hydrogen plasma treatment time is important for increasing the SERS intensity. Using a hydrogen plasma time smaller than the oxygen plasma treatment time leads to incomplete reduction of the oxidized silver film and a lower SERS intensity. The use of equal treatment times using oxygen and hydrogen plasma (20 min $\mathrm{O}_{2}$ plasma and 20 min $\mathrm{H}_{2}$ plasma) increases the SERS intensity further. Using a hydrogen plasma treatment time is higher than that used for oxygen plasma results in a higher SERS enhancement, as it is observed for 15 min oxygen plasma and 20 min hydrogen plasma treatment due to the more complete reduction of the oxidized silver films. Increasing the hydrogen plasma reduction treatment time to $30 \mathrm{~min}$ does not lead to a further increase in the SERS enhancement. Instead there is a slight decrease in the SERS enhancement as excess hydrogen plasma treatment beyond the reduction process results in etching of the silver film: This widens the pores of the formed nanoporous silver network and decreases the SERS enhancement. A decrease in the used gas flow for oxygen and hydrogen as well as the decrease of the used plasma power will result in a decrease in the SERS enhancement with the latter having a more pronounced effect on the SERS enhancement. At low plasma power the surface is modified to a much lower extent leading to a much less nanoporous network (Figure S13, Supporting Information File 1), which is the reason for the low SERS intensities obtained.

To understand if the plasma gas itself used for the reduction process has an effect on the SERS performance, reduction with (i) argon and (ii) nitrogen was studied using oxygen as well as air as oxidizing plasma (Figure 14c,d). The obtained SERS intensities for $10^{-6} \mathrm{M} \mathrm{RhB}$ at $621 \mathrm{~cm}^{-1}$ (excitation wavelength $632.8 \mathrm{~nm}$ ) reveal that argon plasma is more efficient irrespective of the oxidizing plasma used. This can be attributed to the lower reduction efficiency of nitrogen plasma [86].

\section{Comparison of the enhancement performance of different SERS substrates}

A comparison of different SERS substrates a) a $200 \mathrm{~nm}$ sputtered silver film modified by different plasma treatments, b) an as-sputtered $200 \mathrm{~nm}$ silver film and c) a commercial SERS substrate (SEM, Figure S19, Supporting Information File 1) 

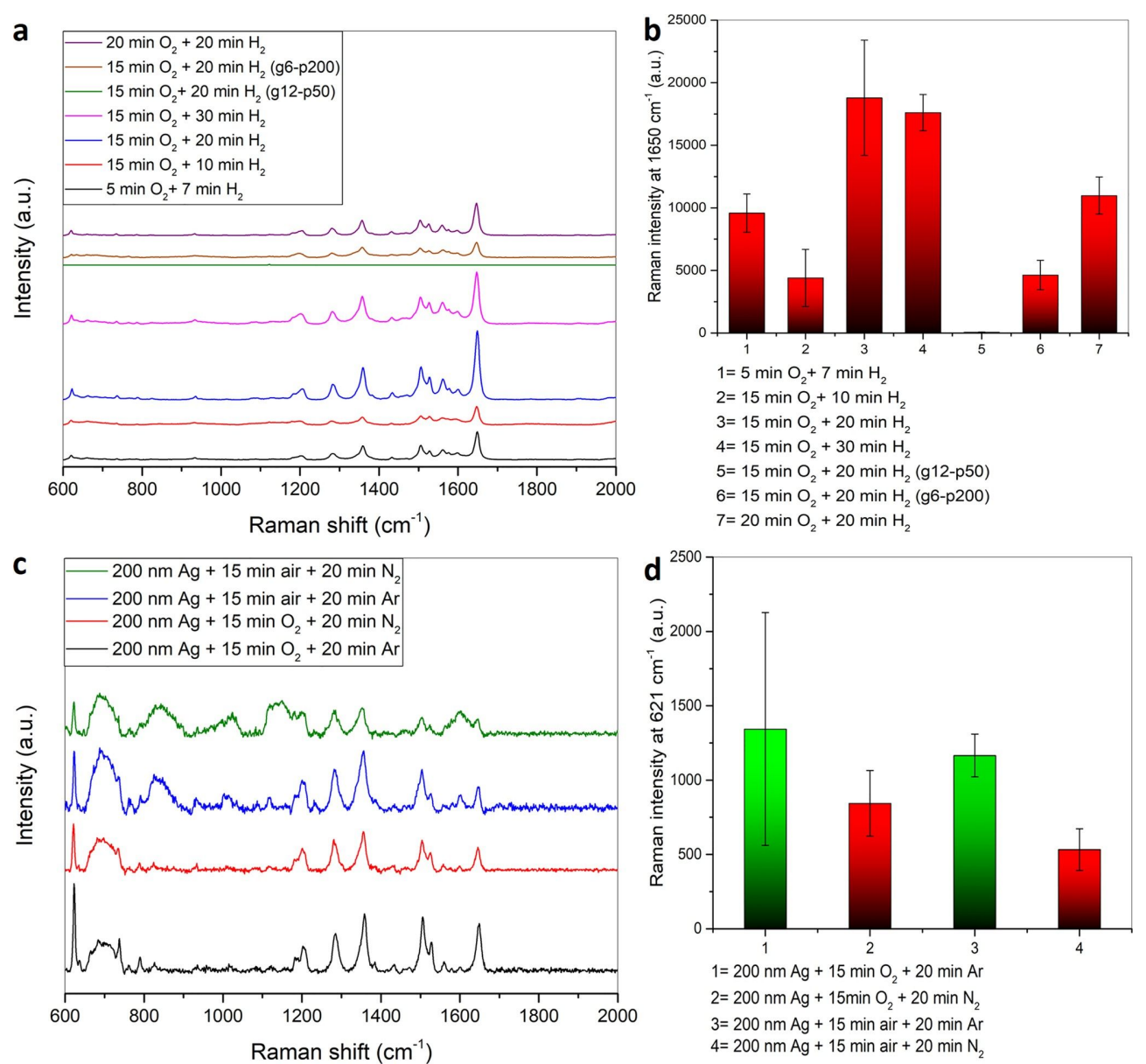

Figure 14: (a) SERS spectra of $10^{-6} \mathrm{M}$ RhB on a $200 \mathrm{~nm}$ silver film treated with different times and parameters of oxygen and hydrogen plasma using $514.5 \mathrm{~nm}$ laser as excitation source. (b) Comparison of the average Raman intensities at $1650 \mathrm{~cm}^{-1}$. (c) SERS spectra of $10^{-6} \mathrm{M} \mathrm{RhB}$ on a $200 \mathrm{~nm}$ silver film treated with different oxidizing and reducing plasmas using $632.8 \mathrm{~nm}$ laser. (d) Comparison of the average Raman intensities at $621 \mathrm{~cm}^{-1}$.

consisting of silver nanoparticles on a paper substrate using $10^{-6} \mathrm{M} \mathrm{RhB}$ as probe at an excitation wavelength of $632.8 \mathrm{~nm}$ is given in Figure 15a,b and Table S3 (Supporting Information File 1). As expected the commercial SERS substrate displays a higher SERS activity than the as-sputtered $200 \mathrm{~nm}$ silver film. However, the SERS enhancement of the as-sputtered $200 \mathrm{~nm}$ silver film can be greatly enhanced by an appropriate plasma treatment leading to a 30 -fold enhancement compared to a commercial SERS substrate and to an about 1200-fold enhancement when compared with an untreated $200 \mathrm{~nm}$ sputtered silver film.

A further comparison of the SERS substrates was done at an excitation wavelength of $532 \mathrm{~nm}$ (Figure 15c,d and Table S3, Supporting Information File 1). A comparison of the group of the plasma treated ultrathin $10 \mathrm{~nm}$ silver films and the plasma treated $200 \mathrm{~nm}$ silver films shows that the SERS intensity obtained with the untreated $10 \mathrm{~nm}$ silver film is higher than with the untreated $200 \mathrm{~nm}$ film (Figure 15c,d and Table S3). For both thicknesses a plasma treatment results in an increase in the SERS intensity. However, in case of $10 \mathrm{~nm}$ silver films, a short plasma treatment of up to $10 \mathrm{~min}$ is already sufficient to yield a significant increase in the SERS intensity of the analyte compared to the untreated silver films considering the single plasma treatments (argon, nitrogen or hydrogen). For these single plasma treatments, the ultrathin transparent silver films are superior compared to their thicker, non-transparent analogues. In case of the oxidation/reduction plasma treatment, the $200 \mathrm{~nm}$ silver films result in better SERS enhancements as they provide more volume for the formation of a continuous and deep nanoporous silver network. In the ultrathin $10 \mathrm{~nm}$ silver film the oxidation/reduction plasma treatment results in the formation of a number of isolated islands (Figure S20, Supporting Information File 1) compared to the continuous silver network as in case of the thicker $200 \mathrm{~nm}$ silver film. Therefore, in the $200 \mathrm{~nm}$ silver films more adsorption sites for the analyte are created and an increased SERS effect is observed for a particular concentration of RhB. Thus, for the $10 \mathrm{~nm}$ silver films hydrogen and 

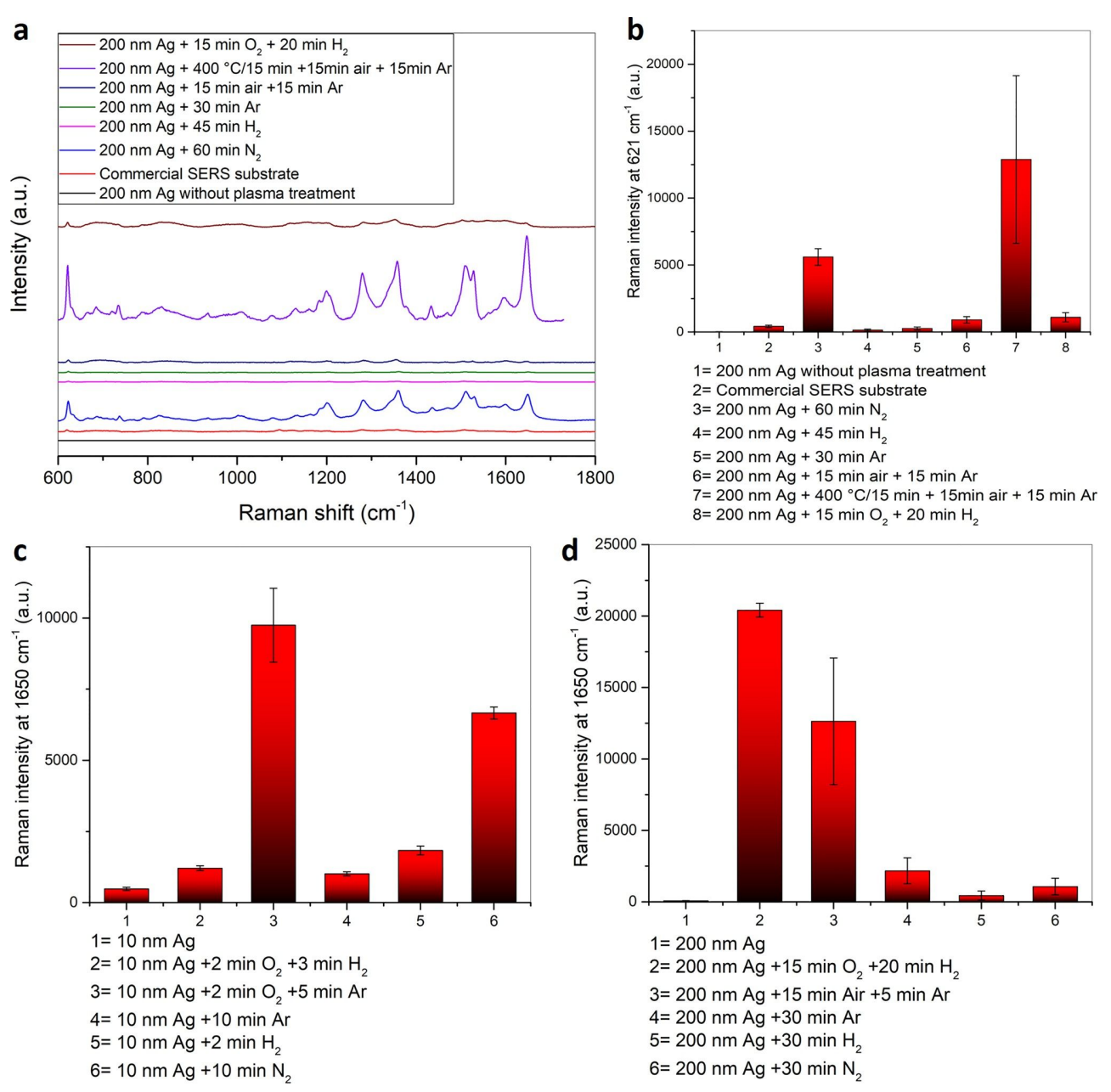

Figure 15: (a) Comparison of the SERS spectra of $10^{-6} \mathrm{M} \mathrm{RhB}$ on different SERS substrates and on a commercial SERS substrate using a $632.8 \mathrm{~nm}$ laser. (b) Comparison of the average Raman intensities at $621 \mathrm{~cm}^{-1}$. Comparison of the average Raman intensities at $1650 \mathrm{~cm}{ }^{-1}$ on different SERS substrates produced through different plasma treatments on (c) $10 \mathrm{~nm}$ and (d) $200 \mathrm{~nm}$ sputtered silver films using a $532 \mathrm{~nm}$ laser.

argon were tested as reducing plasma. It was found that using argon plasma as the reducing plasma yielded SERS substrates with higher SERS enhancement probably due to the fact that hydrogen plasma treatment partially results in etching of the silver islands in addition to the reduction. For the $200 \mathrm{~nm}$ silver films the oxidation/reduction plasma treatment is more efficient than a single plasma treatment in the formation of efficient SERS substrates.

In order to scrutinize the wavelength-dependence of different SERS substrates a comparison of SERS substrates produced by oxidation through air plasma and reduction through argon plasma with different reduction times was undertaken (Figure 16). The SERS performance of these substrates subjected to lower argon plasma reduction time at $532 \mathrm{~nm}$ excitation is much higher and the performance decreases rapidly with increasing argon plasma reduction time. This trend cannot be seen when using $632.8 \mathrm{~nm}$ as excitation wavelength where the SERS performance does not change much with increasing argon plasma reduction time.

Raman mapping of the strongest vibration mode of $\mathrm{RhB}$ at $v=1650 \mathrm{~cm}^{-1}(-\mathrm{COOH})$ on different Ag substrates (different thicknesses and plasma treatment conditions) reveals the overall uniformity of this characteristic absorption. Moreover, the different SERS substrates show good enhancement factors and uniformity as obtained from the Raman maps of $10^{-6} \mathrm{M}$ concentration of RhB on these substrates (Figure S21, Supporting Information File 1).

It is known that the SERS activity can deteriorate due to surface oxidation of the silver surface [88]. For increasing the long-term stability of SERS active silver films we have studied a thin layer of dielectric $\mathrm{Al}_{2} \mathrm{O}_{3}$ as protective coating [89]. A 

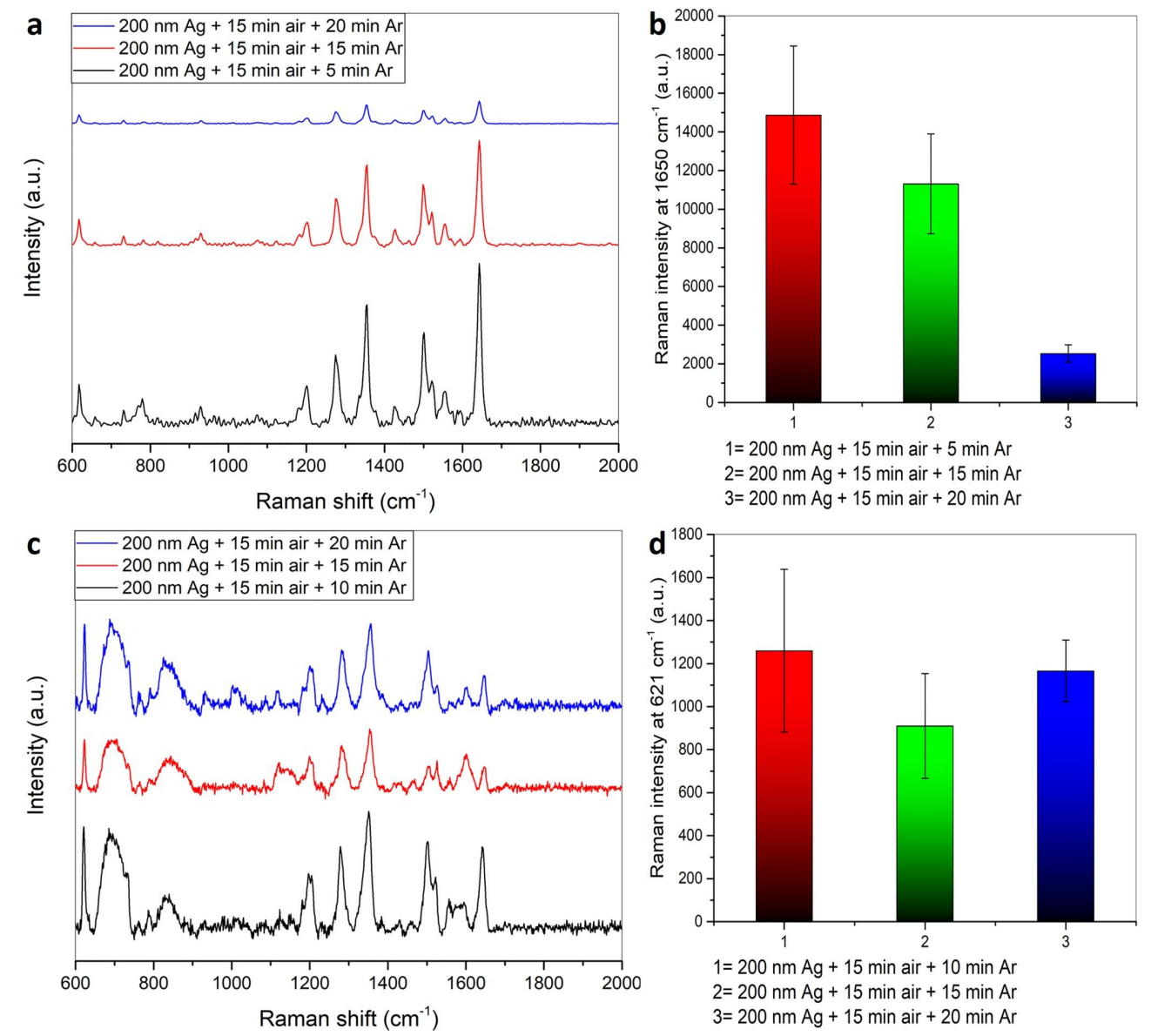

Figure 16: Comparison of the SERS spectra of $10^{-6} \mathrm{M}$ RhB on different SERS substrates prepared through oxidation of $200 \mathrm{~nm}$ silver film with air plasma (g12-p200) for $15 \mathrm{~min}$ followed by reduction with an argon plasma (g16.7-p200) for different times using (a) $532 \mathrm{~nm}$ and (c) $632.8 \mathrm{~nm}$ laser. Comparison of the average Raman intensities at (b) $1650 \mathrm{~cm}^{-1}\left(532 \mathrm{~nm}\right.$ laser excitation) and (d) $621 \mathrm{~cm}^{-1}$ (632.8 nm laser excitation) on the corresponding substrates.

$1 \mathrm{~nm}$ thick $\mathrm{Al}_{2} \mathrm{O}_{3}$ film was deposited on top of the nanoporous silver film by ALD before adding the probe molecule RhB. The influence in SERS activity was compared immediately after deposition and after two weeks. Not unexpectedly, the $\mathrm{Al}_{2} \mathrm{O}_{3}$ layer reduces the SERS signal significantly as the analyte molecules are not in direct contact with the silver surface anymore (Figure S22, Supporting Information File 1). However, characteristic signals of $\mathrm{RhB}$ are still detectable and allow for a secure identification of RhB. Even after two weeks of storage the SERS substrate without $\mathrm{Al}_{2} \mathrm{O}_{3}$ exhibits great SERS performance superior to that of the $\mathrm{Al}_{2} \mathrm{O}_{3}$-coated SERS substrate.

The idea of using plasma treatment for cleaning the used SERS substrates without greatly modifying their response was also tested. This would enable an inexpensive re-use of the SERS substrates. First, the SERS spectrum of $10^{-6} \mathrm{M} \mathrm{RhB}$ on a $200 \mathrm{~nm}$ sputtered silver film was obtained. An argon plasma with a gas flow of $16.7 \mathrm{sccm}$ at $50 \mathrm{~W}$ for 5 min was sufficient to remove the analyte completely (Figure S23a, Supporting Information File 1). Re-application of RhB to the cleaned SERS substrate gave an SERS spectrum equivalent to that before cleaning which proofs that the surface has not been altered extensively by the mild plasma cleaning procedure. A second attempt to clean the SERS substrate under the same conditions also completely removes the analyte providing a clean baseline. The same procedure has been also tested on an older SERS substrate $\left(200 \mathrm{~nm} \mathrm{Ag}+15 \operatorname{min~}_{2}+20 \operatorname{min~}_{2}\right.$ ) that was fabricated six months prior to its use (Figure S23b, Supporting Information File 1). Before the first use it was cleaned using the mentioned short cleaning procedure with argon plasma. Then the same substrate was re-used four times with the short cleaning procedure with argon in-between. No decrease of the performance of the SERS substrate was observed. This shows that mild and short plasma treatment can be used effectively for cleaning of the SERS substrates, whereas 
more aggressive and longer plasma treatment can be used to increase the silver surface roughness and complexity yielding more effective SERS substrates from simple silver films.

\section{Conclusion}

This systematic study proves the possibility of increasing the surface roughness of sputtered silver films through application of different rf plasma treatments as an alternative to the widely employed method of electrochemical surface roughening of silver films. Different reactive plasma gas compositions as well as different plasma parameters used in the particular plasma treatments result in a variety of different SERS silver substrates with tunable morphology and attractive enhancement factors. A combination of an oxidizing plasma together with a reducing plasma results in the formation of complex three-dimensional silver morphologies showing a huge enhancement factor due to the formation of SERS hot spots. The SERS enhancement of the as-sputtered $200 \mathrm{~nm}$ silver film is greatly enhanced by an appropriate plasma treatment reaching about 30 -fold enhancement compared to a commercial SERS substrate and about 1200 -fold compared to the untreated silver film. At the same time it was also found that ultrathin transparent silver films can be used as efficient SERS substrates. Heating of the silver film under a subsequent oxidative/reductive rf plasma treatment enables the formation of a silver-nanosponge morphology directly on the glass substrate. The morphologies fabricated by various plasma treatment processes are stable over the course of several weeks and can even be recovered and re-used after initial analytical use through employing a mild argon plasma treatment.

To summarize, rf plasma treatment offers flexibility in obtaining a wide variety of silver morphologies on a substrate starting from a thin sputter deposited silver film. We believe that this technique offers an attractive and efficient way for a straightforward fabrication of SERS substrates even based on other host metals.

\section{Supporting Information}

\section{Supporting Information File 1}

Additional experimental data.

[https://www.beilstein-journals.org/bjnano/content/ supplementary/2190-4286-9-263-S1.pdf]

\section{Acknowledgements}

The authors thank S. Heinschke and Dr. J. Engstler (both at TU Darmstadt) for XRD measurements and TEM analyses, respectively. TEM studies were performed at the Ernst-Ruska Center (ERC) at the Forschungszentrum (FZ) Jülich under contract ERC-TUD1. XPS and Auger measurements were carried out at the Karlsruhe Nano Micro Facility at KIT under the KNMF program. SO acknowledges the Egyptian Ministry of Higher Education (MoHE) and the German Academic Exchange Service (DAAD) for support through the GermanEgyptian Research Scholarship (GERLS) program (funding program number 57030312).

\section{ORCID ${ }^{\circledR}$ iDs}

Jörg J. Schneider - https://orcid.org/0000-0002-8153-9491

\section{References}

1. Sharma, B.; Frontiera, R. R.; Henry, A.-I.; Ringe, E.; Van Duyne, R. P. Mater. Today 2012, 15, 16-25. doi:10.1016/s1369-7021(12)70017-2

2. Fleischmann, M.; Hendra, P. J.; McQuillan, A. J. Chem. Phys. Lett. 1974, 26, 163-166. doi:10.1016/0009-2614(74)85388-1

3. Albrecht, M. G.; Creighton, J. A. J. Am. Chem. Soc. 1977, 99, 5215-5217. doi:10.1021/ja00457a071

4. Jeong, J. W.; Arnob, M. M. P.; Baek, K.-M.; Lee, S. Y.; Shih, W.-C.; Jung, Y. S. Adv. Mater. 2016, 28, 8695-8704. doi:10.1002/adma.201602603

5. Kneipp, K. Phys. Today 2007, 60, 40-46. doi:10.1063/1.2812122

6. Guerrini, L.; Graham, D. Chem. Soc. Rev. 2012, 41, 7085. doi:10.1039/c2cs35118h

7. Mosier-Boss, P. Nanomaterials 2017, 7, 142. doi:10.3390/nano7060142

8. Liu, Y.-C.; Yu, C.-C.; Sheu, S.-F. J. Mater. Chem. 2006, 16, 3546. doi:10.1039/b609417a

9. Yang, K.-H.; Liu, Y.-C.; Yu, C.-C. J. Mater. Chem. 2008, 18, 4849-4855. doi:10.1039/b808516a

10. Cao, P.; Gu, R.; Tian, Z. J. Phys. Chem. B 2003, 107, 769-777. doi:10.1021/jp026747o

11. Yang, K.-H.; Liu, Y.-C.; Yu, C.-C. Langmuir 2010, 26, 11512-11517. doi:10.1021/la100235x

12. Fang, C.; Ellis, A. V.; Voelcker, N. H. J. Electroanal. Chem. 2011, 659, 151-160. doi:10.1016/j.jelechem.2011.05.016

13. Zhou, X.; Zhou, F.; Liu, H.; Yang, L.; Liu, J. Analyst 2013, 138, 5832. doi:10.1039/c3an00914a

14. Liang, H.; Li, Z.; Wang, W.; Wu, Y.; Xu, H. Adv. Mater. 2009, 21 , 4614-4618. doi:10.1002/adma.200901139

15. Farcau, C.; Potara, M.; Leordean, C.; Boca, S.; Astilean, S. Analyst 2013, 138, 546-552. doi:10.1039/c2an36440a

16. Sharma, B.; Fernanda Cardinal, M.; Kleinman, S. L.; Greeneltch, N. G.; Frontiera, R. R.; Blaber, M. G.; Schatz, G. C.; Van Duyne, R. P. MRS Bull. 2013, 38, 615-624. doi:10.1557/mrs.2013.161

17. Tastekova, E. A.; Polyakov, A. Y.; Goldt, A. E.; Sidorov, A. V.; Oshmyanskaya, A. A.; Sukhorukova, I. V.; Shtansky, D. V.; Grünert, W.; Grigorieva, A. V. Beilstein J. Nanotechnol. 2018, 9, 880-889. doi:10.3762/bjnano.9.82

18. Jensen, T. R.; Malinsky, M. D.; Haynes, C. L.; Van Duyne, R. P. J. Phys. Chem. B 2000, 104, 10549-10556. doi:10.1021/jp002435e

19. Haynes, C. L.; Van Duyne, R. P. J. Phys. Chem. B 2001, 105, 5599-5611. doi:10.1021/jp010657m

20. Dick, L. A.; McFarland, A. D.; Haynes, C. L.; Van Duyne, R. P. J. Phys. Chem. B 2002, 106, 853-860. doi:10.1021/jp013638I

21. Haynes, C. L.; Van Duyne, R. P. J. Phys. Chem. B 2003, 107, 7426-7433. doi:10.1021/jp027749b 
22. Zhang, X.; Yonzon, C. R.; Young, M. A.; Stuart, D. A.; Van Duyne, R. P. IEE Proc.: Nanobiotechnol. 2005, 152, 195-206. doi:10.1049/ip-nbt:20050009

23. Lin, W.-C.; Liao, L.-S.; Chen, Y.-H.; Chang, H.-C.; Tsai, D. P.; Chiang, H.-P. Plasmonics 2011, 6, 201-206. doi:10.1007/s11468-010-9188-X

24. Yan, W.-G.; Qi, J.-W.; Li, Z.-B.; Tian, J.-G. Plasmonics 2014, 9 , 565-571. doi:10.1007/s11468-013-9665-0

25. Zhu, Z.; Li, Q.; Bai, B.; Fan, S. Nanoscale Res. Lett. 2014, 9, 25. doi:10.1186/1556-276x-9-25

26. Huebner, U.; Boucher, R.; Schneidewind, H.; Cialla, D.; Popp, J. Microelectron. Eng. 2008, 85, 1792-1794. doi:10.1016/j.mee.2008.05.005

27. Yan, B.; Thubagere, A.; Premasiri, W. R.; Ziegler, L. D.; Dal Negro, L.; Reinhard, B. M. ACS Nano 2009, 3, 1190-1202. doi:10.1021/nn800836f

28. Deng, X.; Braun, G. B.; Liu, S.; Sciortino, P. F., Jr.; Koefer, B.; Tombler, T.; Moskovits, M. Nano Lett. 2010, 10, 1780-1786. doi:10.1021/nl1003587

29. Im, H.; Bantz, K. C.; Lindquist, N. C.; Haynes, C. L.; Oh, S.-H. Nano Lett. 2010, 10, 2231-2236. doi:10.1021/nl1012085

30. Dinish, U. S.; Yaw, F. C.; Agarwal, A.; Olivo, M. Biosens. Bioelectron. 2011, 26, 1987-1992. doi:10.1016/j.bios.2010.08.069

31. Ahn, H.-J.; Thiyagarajan, P.; Jia, L.; Kim, S.-I.; Yoon, J.-C.; Thomas, E. L.; Jang, J.-H. Nanoscale 2013, 5, 1836. doi:10.1039/c3nr33498h

32. Gillibert, R.; Sarkar, M.; Bryche, J.-F.; Yasukuni, R.; Moreau, J.; Besbes, M.; Barbillon, G.; Bartenlian, B.; Canva, M.; de la Chapelle, M. L. Nanotechnology 2016, 27, 115202. doi:10.1088/0957-4484/27/11/115202

33. Alvarez-Puebla, R.; Cui, B.; Bravo-Vasquez, J.-P.; Veres, T.; Fenniri, H. J. Phys. Chem. C 2007, 111, 6720-6723. doi:10.1021/jp070906s

34. Krishnamoorthy, S.; Krishnan, S.; Thoniyot, P.; Low, H. Y. ACS Appl. Mater. Interfaces 2011, 3, 1033-1040. doi:10.1021/am1011518

35. Chen, Y.-C.; Young, R. J.; Macpherson, J. V.; Wilson, N. R. J. Phys. Chem. C 2007, 111, 16167-16173. doi:10.1021/jp073771z

36. Altun, A. O.; Bond, T. C.; Park, H. G. Proc. SPIE 2014, 9168, 916809. doi:10.1117/12.2061539

37. Zhang, J.; Zhang, X.; Lai, C.; Zhou, H.; Zhu, Y. Opt. Express 2014, 22, 21157-21166. doi:10.1364/oe.22.021157

38. Zhang, K.; Ji, J.; Fang, X.; Yan, L.; Liu, B. Analyst 2015, 140, 134-139. doi:10.1039/c4an01473a

39. Jin, Y.; Wang, Y.; Chen, M.; Xiao, X.; Zhang, T.; Wang, J.; Jiang, K.; Fan, S.; Li, Q. ACS Appl. Mater. Interfaces 2017, 9, 32369-32376. doi:10.1021/acsami.7b08807

40. Srichan, C.; Ekpanyapong, M.; Horprathum, M.; Eiamchai, P.; Nuntawong, N.; Phokharatkul, D.; Danvirutai, P.; Bohez, E.; Wisitsoraat, A.; Tuantranont, A. Sci. Rep. 2016, 6, 23733. doi:10.1038/srep23733

41. Fang, H.; Zhang, C. X.; Liu, L.; Zhao, Y. M.; Xu, H. J. Biosens. Bioelectron. 2015, 64, 434-441. doi:10.1016/j.bios.2014.09.053

42. Barbillon, G.; Sandana, V. E.; Humbert, C.; Bélier, B.; Rogers, D. J.; Teherani, F. H.; Bove, P.; McClintock, R.; Razeghi, M. J. Mater. Chem. C 2017, 5, 3528-3535. doi:10.1039/c7tc00098g

43. Shao, F.; Lu, Z.; Liu, C.; Han, H.; Chen, K.; Li, W.; He, Q.; Peng, H.; Chen, J. ACS Appl. Mater. Interfaces 2014, 6, 6281-6289. doi:10.1021/am4045212
44. Chen, J.; Qin, G.; Chen, Q.; Yu, J.; Li, S.; Cao, F.; Yang, B.; Ren, Y. J. Mater. Chem. C 2015, 3, 4933-4944. doi:10.1039/c5tc00717h

45. Asiala, S. M.; Marr, J. M.; Gervinskas, G.; Juodkazis, S.; Schultz, Z. D. Phys. Chem. Chem. Phys. 2015, 17, 30461-30467. doi:10.1039/c5cp04506a

46. Seniutinas, G.; Gervinskas, G.; Verma, R.; Gupta, B. D.; Lapierre, F.; Stoddart, P. R.; Clark, F.; McArthur, S. L.; Juodkazis, S. Opt. Express 2015, 23, 6763. doi:10.1364/oe.23.006763

47. Zhang, C.; Jiang, S. Z.; Yang, C.; Li, C. H.; Huo, Y. Y.; Liu, X. Y.; Liu, A. H.; Wei, Q.; Gao, S. S.; Gao, X. G.; Man, B. Y. Sci. Rep. 2016, 6, 25243. doi:10.1038/srep25243

48. Zuo, Z.; Zhu, K.; Gu, C.; Wen, Y.; Cui, G.; Qu, J. Appl. Surf. Sci. 2016, 379, 66-72. doi:10.1016/j.apsusc.2016.04.022

49. Schierhorn, M.; Lee, S. J.; Boettcher, S. W.; Stucky, G. D.; Moskovits, M. Adv. Mater. 2006, 18, 2829-2832. doi:10.1002/adma.200601254

50. Wang, H.-H.; Liu, C.-Y.; Wu, S.-B.; Liu, N.-W.; Peng, C.-Y.; Chan, T.-H.; Hsu, C.-F.; Wang, J.-K.; Wang, Y.-L. Adv. Mater. 2006, 18, 491-495. doi:10.1002/adma.200501875

51. Choi, D.; Choi, Y.; Hong, S.; Kang, T.; Lee, L. P. Small 2010, 6 , 1741-1744. doi:10.1002/smll.200901937

52. Das, G.; Patra, N.; Gopalakrishnan, A.; Zaccaria, R. P.; Toma, A.; Thorat, S.; Di Fabrizio, E.; Diaspro, A.; Salerno, M. Analyst 2012, 137, 1785-1792. doi:10.1039/c2an16022f

53. Chaney, S. B.; Shanmukh, S.; Dluhy, R. A.; Zhao, Y.-P. Appl. Phys. Lett. 2005, 87, 031908. doi:10.1063/1.1988980

54. Shanmukh, S.; Jones, L.; Driskell, J.; Zhao, Y.; Dluhy, R.; Tripp, R. A. Nano Lett. 2006, 6, 2630-2636. doi:10.1021/nl061666f

55. Negri, P.; Dluhy, R. A. J. Biophotonics 2013, 6, 20-35. doi:10.1002/jbio.201200133

56. He, Y.; Fu, J.; Zhao, Y. Front. Phys. 2014, 9, 47-59. doi:10.1007/s11467-013-0357-1

57. Jiao, Y.; Ryckman, J. D.; Ciesielski, P. N.; Escobar, C. A.; Jennings, G. K.; Weiss, S. M. Nanotechnology 2011, 22, 295302. doi:10.1088/0957-4484/22/29/295302

58. Qi, J.; Motwani, P.; Gheewala, M.; Brennan, C.; Wolfe, J. C.; Shih, W.-C. Nanoscale 2013, 5, 4105-4109. doi:10.1039/c2nr33242f

59. Li, R.; Liu, X. J.; Wang, H.; Wu, Y.; Chu, X. M.; Lu, Z. P. Corros. Sci. 2014, 84, 159-164. doi:10.1016/j.corsci.2014.03.023

60. Liu, K.; Bai, Y.; Zhang, L.; Yang, Z.; Fan, Q.; Zheng, H.; Yin, Y.; Gao, C. Nano Lett. 2016, 16, 3675-3681. doi:10.1021/acs.nanolett.6b00868

61. Hoppmann, E. P.; Yu, W. W.; White, I. M. Methods 2013, 63, 219-224. doi:10.1016/j.ymeth.2013.07.010

62. Polavarapu, L.; Porta, A. L.; Novikov, S. M.; Coronado-Puchau, M.; Liz-Marzán, L. M. Small 2014, 10, 3065-3071. doi:10.1002/smll.201400438

63. Liston, E. M. J. Adhes. 1989, 30, 199-218. doi:10.1080/00218468908048206

64. Jelil, R. A. J. Mater. Sci. 2015, 50, 5913-5943. doi:10.1007/s10853-015-9152-4

65. Tendero, C.; Tixier, C.; Tristant, P.; Desmaison, J.; Leprince, P. Spectrochim. Acta, Part B 2006, 61, 2-30. doi:10.1016/j.sab.2005.10.003

66. Fraser, D. B.; Westwood, D. W. In Handbook of plasma processing technology: fundamentals, etching, deposition, and surface interactions; Rossnagel, S.; Cuomo, J.; Westwood, W., Eds.; Noyes Publications: New Jersey, NJ, U.S.A., 1990; pp 2-12. 
67. Petlin, D. G.; Tverdokhlebov, S. I.; Anissimov, Y. G. J. Controlled Release 2017, 266, 57-74. doi:10.1016/j.jconrel.2017.09.023

68. Tiller, H.-J.; Demme, U.; Lenke, D.; Bühner, P.; Meyer, K. Krist. Tech. 1975, 10, K103-K108. doi:10.1002/crat.19750101018

69. Kim, S. Y.; Hong, K.; Kim, K.; Yu, H. K.; Kim, W.-K.; Lee, J.-L. J. Appl. Phys. 2008, 103, 076101. doi:10.1063/1.2874495

70. Kim, H.; Shin, K.-Y.; Kang, H.-S.; Lee, S.-H.; Kim, J.-M. Microsyst. Technol. 2016, 22, 1135-1142. doi:10.1007/s00542-015-2595-3

71. Shanmugan, S.; Mutharasu, D.; Kamarulazizi, I. Eur. Phys. J.: Appl. Phys. 2012, 58, 10802. doi:10.1051/epjap/2012110466

72. Kinnan, M. K.; Kumbhar, A.; Chumanov, G. Appl. Spectrosc. 2008, 62, 721-726. doi:10.1366/000370208784909463

73. Ma, C.; Trujillo, M. J.; Camden, J. P. ACS Appl. Mater. Interfaces 2016, 8, 23978-23984. doi:10.1021/acsami.6b08191

74. Kruth, M.; Meertens, D.; Tillmann, K. J. Large-Scale Res. Facil. 2016, 2, A59. doi:10.17815/jlsrf-2-105

75. Chen, F. F.; Chang, J. P. Lecture Notes on Principles of Plasma Processing; Springer US: Boston, MA, U.S.A., 2003. doi:10.1007/978-1-4615-0181-7

76. Liston, E. M.; Martinu, L.; Wertheimer, M. R. J. Adhes. Sci. Technol. 1993, 7, 1091-1127. doi:10.1163/156856193x00600

77. Santoro, G.; Yu, S.; Schwartzkopf, M.; Zhang, P.; Koyiloth Vayalil, S.; Risch, J. F. H.; Rübhausen, M. A.; Hernández, M.; Domingo, C.; Roth, S. V. Appl. Phys. Lett. 2014, 104, 243107. doi:10.1063/1.4884423

78. Choi, T.-S.; Levitin, G.; Hess, D. W. ECS J. Solid State Sci. Technol. 2013, 2, P275-P281. doi:10.1149/2.012306jss

79. Wagner, A. J.; Fairbrother, D. H.; Reniers, F. Plasmas Polym. 2003, 8, 119-134. doi:10.1023/a:1023942211714

80. Depla, D.; De Gryse, R. Vacuum 2003, 69, 529-536. doi:10.1016/s0042-207x(02)00602-4

81. McGuire, G. E. Auger Electron Spectroscopy Reference Manual; Plenum Press: New York, NY, U.S.A., 1979. doi:10.1007/978-1-4757-1702-0

82. El Mel, A.-A.; Stephant, N.; Hamon, J.; Thiry, D.; Chauvin, A.; Chettab, M.; Gautron, E.; Konstantinidis, S.; Granier, A.; Tessier, P.-Y. Nanoscale 2016, 8, 141-148. doi:10.1039/c5nr07145c

83. Bielmann, M.; Ruffieux, P.; Schwaller, P.; Sudan, P.; Schlapbach, L.; Gröning, P. J. Electron. Mater. 2002, 31, 1316-1320. doi:10.1007/s11664-002-0114-7

84. Jelić, D.; Penavin-Škundrić, J.; Majstorović, D.; Mentus, S. Thermochim. Acta 2011, 526, 252-256. doi:10.1016/j.tca.2011.10.001

85. Jacquet, P.; Podor, R.; Ravaux, J.; Teisseire, J.; Gozhyk, I.; Jupille, J.; Lazzari, R. Scr. Mater. 2016, 115, 128-132.

doi:10.1016/j.scriptamat.2016.01.005

86. Ovchinnikov, V. Reduction of Silver Oxide Film in Inert Gas Plasma. In The Tenth International Conference on Quantum, Nano/Bio, and Micro Technologies, 2016; pp 6-11.

87. Reinhold, I.; Hendriks, C. E.; Eckardt, R.; Kranenburg, J. M.; Perelaer, J.; Baumann, R. R.; Schubert, U. S. J. Mater. Chem. 2009, 19, 3384-3388. doi:10.1039/b823329b

88. Han, Y.; Lupitskyy, R.; Chou, T.-M.; Stafford, C. M.; Du, H.; Sukhishvili, S. Anal. Chem. 2011, 83, 5873-5880. doi:10.1021/ac2005839

89. Yüksel, S.; Ziegler, M.; Goerke, S.; Hübner, U.; Pollok, K.; Langenhorst, F.; Weber, K.; Cialla-May, D.; Popp, J. J. Phys. Chem. C 2015, 119, 13791-13798. doi:10.1021/acs.jpcc.5b01389

\section{License and Terms}

This is an Open Access article under the terms of the Creative Commons Attribution License (http://creativecommons.org/licenses/by/4.0). Please note that the reuse, redistribution and reproduction in particular requires that the authors and source are credited.

The license is subject to the Beilstein Journal of Nanotechnology terms and conditions: (https://www.beilstein-journals.org/bjnano)

The definitive version of this article is the electronic one which can be found at:

doi:10.3762/bjnano.9.263 